Article

\title{
Deformation Characteristics of the Shear Zone and Movement of Block Stones in Soil-Rock Mixtures Based on Large-Sized Shear Test
}

\author{
Zhiqing $\mathrm{Li}^{1,2,3, *}$, Feng $\mathrm{Hu}^{1,2,3}$, Shengwen $\mathrm{Qi}^{1,2,3}$, Ruilin $\mathrm{Hu}^{1,2,3}$, Yingxin Zhou ${ }^{4}$ and Yawei Bai ${ }^{5}$ \\ 1 Key Laboratory of Shale Gas and Geoengineering, Institute of Geology and Geophysics, Chinese Academy \\ of Sciences, Beijing 100029, China; hufeng@mail.iggcas.ac.cn (F.H.); qsw@mail.iggcas.ac.cn (S.Q.); \\ hrl@mail.iggcas.ac.cn (R.H.) \\ 2 College of Earth and Planetary Science, University of Chinese Academy of Sciences, Beijing 100049, China \\ 3 Innovation Academy of Earth Science, Chinese Academy of Sciences, Beijing 100029, China \\ 4 Yunnan Chuyao Expressway Construction Headquarters, Chuxiong 675000, China; zhouyx@gmail.com \\ 5 Henan Yaoluanxi Expressway Construction Co. LTD, Luanchuan 471521, China; byw@gmail.com \\ * Correspondence: lizhiq-2002@163.com or lizhiqing@mail.iggcas.ac.cn; Tel.: +86-13671264387
}

Received: 27 July 2020; Accepted: 15 September 2020; Published: 17 September 2020

\begin{abstract}
Soil-rock mixtures (SRM) have the characteristics of distinct heterogeneity and an obvious structural effect, which make their physical and mechanical properties very complex. This study aimed to investigate the deformation properties and failure mode of the shear zone as well as the movement of block stones in SRM experimentally, not only considering SRM shear strength. The particle composition and proportion of specimens were based on field samples from an SRM slope along national highway 318 in Xigaze, Tibet. Shear zone deformation tests were carried out using an SRM-1000 large-sized geotechnical apparatus controlled by a motor servo, considering the effects of different stone contents by mass $(0,30 \%, 50 \%, 70 \%)$, vertical pressures $(50,100,200,300$, and $400 \mathrm{kPa})$, and block stone sizes $(9.5-19.0,19.0-31.5$, and $31.5-53.0 \mathrm{~mm})$. The characteristics of the shear zone deformation and block stone interactions were monitored by placing aluminum wires and dry ash in holes in the specimens. The results showed that the stone content $30 \%$ and $70 \%$ were two critical thresholds to determine the deformation characteristics of SRM. Under the conditions of high stone content and large particle size, the stones throughout the shear surface tended to extrude and roll during the shear process. The block stones around the shear surface were mainly affected by dilatancy and exhibited extrusion, particle breakage, and redistribution. The deformation pattern could be considered as be analogous to push-type shear deformation from the back to front or composite shear deformation from the front and back to the middle of the slope. It is of great importance to study the shear characteristics and deformation evolution of SRM to understand the progressive shear process of the sliding zone and the failure mode of landslides.
\end{abstract}

Keywords: soil-rock mixture (SRM); sand-pebble mixture (SPM); direct shear test; stone content; shear zone; deformation characteristics

\section{Introduction}

Soil-rock mixture (SRM) refers to a type of uneven loose deposit material mainly composed of stone, fine-grained soil, water, and pores that is between a homogeneous soil and fractured rock mass from the quaternary period [1]. SRM landslides are widely distributed in China. There have been 1736 landslides in the $100 \mathrm{~km}^{2}$ area within the catchment of the upper Yangtze River, of which approximately $64 \%$ were SRM landslides [2]. Slip zones of large landslides in the Three Gorges area are commonly set on fine-grained soil horizons with a significant amount of coarse-grained particles, particularly 
gravel-sized particles [3]. There are a large number of slopes in a critical stable state composed of sand-pebble mixture (SPM) mainly composed of pebble, sand, partial clay soil, water, and pores, which is a special type of SRM in Tibet, as shown in Figure 1. SRM landslides have produced serious damage to social security and project construction in the midwestern region of China. Thus, it is of great importance to study the deformation and strength mechanisms, the shear deformation process, and disaster prevention in SRM landslides.

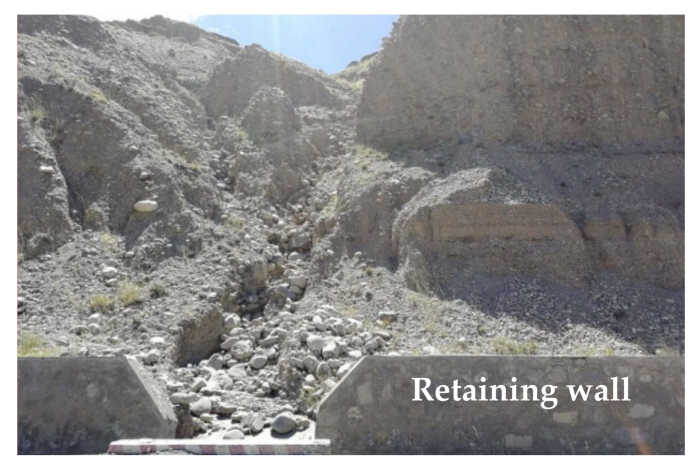

Figure 1. Sand-pebble mixture slope along national highway 318 in Xigaze, Tibet.

SRM can also be referred to as bimsoil [4] or block-in-matrix soil, coarse-grained soil [5-11], granular soil [12-17], or gravelly soil [18,19]. Research on coarse-grained soil, granular soil, or gravelly soil emphasizes the mixing state of the coarse and fine grains. In contrast, SRM research emphasizes the material composition and structural characteristics of the soil. The characteristics and difficulties of SRM research include two main aspects. First, SRM is a discontinuous material with a complex composition. Therefore, it is difficult to characterize the mechanical behavior arising from the high heterogeneity and structural randomness of SRM quantitatively. Second, the structural effect of SRM is prominent. As a result, the strength, deformation, and permeability of the SRM are directly affected by its structural state, including the quantity, size [20], arrangement, shape [21], cementation of the block stones, the porosity [12], and the bedrock surface. The factors affecting the deformation and strength characteristics of SRM are extraordinarily complex [22,23].

To date, SRM studies have mainly concentrated on investigating the strength characteristics experimentally, considering factors such as the stone content, water content, and stone granularity. The effects of the coarse-grained content on the shear strength of SRM have been investigated under saturated and unsaturated conditions [24-28]. The computed tomography (CT) has been used to obtain information about the cutting surface of SRM to reconstruct a three-dimensional model of gravels [29]. Uniaxial compression tests have been used to obtain the strength and cracking characteristics of SRM by preparing remolded specimens [30,31]. Li [32] studied the deformation and strength characteristics of an SRM specimen surface through triaxial tests and a subpixel point identification and measurement system of the sample surface. Zhang et al. [33] carried out triaxial tests on three types of SRM samples with the same stone content, but different grain size distributions containing "oversized rock blocks" to study the macroscopic mechanical behavior of SRM using CT. Direct shear tests have been used to obtain the strength and dilatancy characteristics of sand-gravel mixtures, coarse-grained soil, or granular soil [34-37]. A large number of direct shear tests in situ and large-sized shear tests have been carried out to obtain typical stress-strain curves [38,39]. Miller [40] investigated the strength of SRM with different block rock mass ratios. Cook [41] studied the effects of the block stone content, size, and shape on the engineering properties of compacted silty clay. The distribution and size of block stones in samples in situ are extremely heterogeneous, and thus field shear test data exhibit greater dispersion. Therefore, laboratory direct shear tests are more suitable for studying the strength and deformation characteristics of SRM.

However, there has been less research on the shear deformation behavior of SRM by laboratory tests, particularly on the formation and evolution of the shear zone of SRM during the shearing 
process. Traditional methods such as strain gauges and CT are difficult to apply for large-scale discrete materials like SRM. Owing to the limitations of the test size and observation of the rock block movement, numerical simulations are popular methods. The discrete element method (DEM) was used to investigate the effects of the stone content, stone strength, and stone shape on SRM strength by introducing a shape factor to form a polygonal fracture module [42]. DEM was also used to analyze shear banding in shear tests [43]. Particle flow code (PFC) models were used to simulate stress-strain relationships in SRM biaxial compression tests [44] and shear tests with large dimensions of $500 \times 500 \times 400 \mathrm{~mm}$ [45]. The finite element method was used to analyze the direct strength of direct shear box tests [46] and the mesostructure and mesomechanical characteristics of SRM [47]. Based on DEM, a 3D random mesostructure modeling system of SRM was developed and used to generate a mesostructural model of SRM to simulate shear stress-strain curves [48]. However, these numerical simulation results are only qualitative or semi-quantitative. Table 1 gives the comparison between the sliding zone thickness and sliding body thickness in landslides.

The aim of this study is to investigate the deformation characteristics and failure mode of the shear zone as well as the movement rule for the block stones in SRM from an experimental perspective. This differs from previous studies, which have often focused on changes in the strength properties of SRM. Some deformation studies were conducted using numerical simulations, which largely depended on the selection of the constitutive model, physical parameters, and boundary conditions. Thus, deformation tests of SRM were carried out through large-sized direct shear tests controlled by a motor servo in this study. The deformation characteristics of the shear zone were monitored by placing aluminum wires and dry ash in the specimen holes. Three main structural factors, such as the stone content, overburden vertical pressure, and stone size, were considered to investigate the interaction of the block stones during the deformation process. It is of great importance to study the shear characteristics and deformation evolution of specimens to understand the progressive shear process of the sliding zone and the failure mode of SRM landslides. 
Table 1. Comparison between the sliding zone thickness and sliding body thickness in landslides.

\begin{tabular}{|c|c|c|c|c|c|c|}
\hline Location & Landslide Name & Composition & $\begin{array}{l}\text { Sliding Zone } \\
\text { Thickness, } h(\mathrm{~m})\end{array}$ & $\begin{array}{c}\text { Sliding Body } \\
\text { Thickness, } h^{\prime}(\mathrm{m})\end{array}$ & $h / h^{\prime}(\%)$ & Reference \\
\hline Mengla County in Yunnan & $\mathrm{H}_{1}$ landslide & Crushed stone and clay & $0.4 \sim 0.7$ & 3.0 & $13.3 \sim 23.3$ & [49] \\
\hline Ya'an City in Sichuan & Tiangongsi landslide & Silty clay with pebbles & $0.3 \sim 0.5$ & 4.0 & $7.5 \sim 12.5$ & [50] \\
\hline Guixi City in Guangxi & Jiuxu landslide & Clay, gravel, and weathered rock & $0.3 \sim 4.0$ & 13.3 & $2.3 \sim 30.1$ & [51] \\
\hline Minjiang in Sichuan & $\mathrm{H}_{1}$ landslide & Pebbly silty clay & $0.1 \sim 0.55$ & 5.2 & $1.9 \sim 10.6$ & [52] \\
\hline Tongguan County in Shanxi & Fenghuang mountain $\mathrm{H}_{2}$ landslide & Loess & $<0.5$ & 6.5 & $<7.7$ & [53] \\
\hline Ankang City in Shanxi & Ziyang landslide & Clay with gravel & $0.5 \sim 1.0$ & 6.0 & $8.3 \sim 16.7$ & [54] \\
\hline Puge City in Sichuan & Dacao Village landslide & Silt with gravel & $0.4 \sim 1.5$ & 7.0 & $5.7 \sim 21.4$ & [55] \\
\hline Lanzhou City in Gansu & Bao'ensi landslide & $\begin{array}{l}\text { Silt, mudstone fragments with } \\
\text { sandstone detritus }\end{array}$ & $0.2 \sim 1.0$ & 16.4 & $1.2 \sim 6.1$ & [56] \\
\hline Xuanhan County in Sichuan & Pianyanzi landslide & $\begin{array}{l}\text { Silty clay with weathered mudstone } \\
\text { and sandstone fragments }\end{array}$ & $0.5 \sim 1.2$ & 12.0 & $4.2 \sim 10.0$ & {$[57]$} \\
\hline
\end{tabular}




\section{Test Specimen Preparation}

The particle composition and proportion of the specimens are based on field samples from an SPM slope (Figure 1), which is a special type of SRM slope located along national highway 318 in Xigaze, Tibet. The grain size distribution curve of fine-grained soil is shown in Figure 2. The percentage of fine-grained part less than $0.075 \mathrm{~mm}$ is about $6 \%$. The fine-grained part that has plasticity can be defined as silt sand according to the Chinese standard [58]. Three pebble sizes were used as the coarse-grained part of the SRM by reducing the size of the stones on site $[59,60]$. The density of the block stone was $2.4 \mathrm{~g} / \mathrm{cm}^{3}$. The pebble size ranges from 9.5 to $53.0 \mathrm{~cm}$. The average uniaxial compressive strength of pebbles is $42.6 \mathrm{MPa}$. The pebble was divided into four groups by screening with a stone screen containing square holes [61], as shown in Figure 3. The size of group $L 0$ is less than $5.0 \mathrm{~mm}$; group $L 1$ has a size between 9.5 and $19.0 \mathrm{~mm}$; the size of group $L 2$ is between 19.0 and $31.5 \mathrm{~mm}$; and the size of group $L 3$ is between 31.5 and $53.0 \mathrm{~mm}$. The sizes of 9.5, 19.0, 31.5, and $53.0 \mathrm{~mm}$ correspond to the lengths of the different meshes of the stone screens, according to the Chinese standard [61].

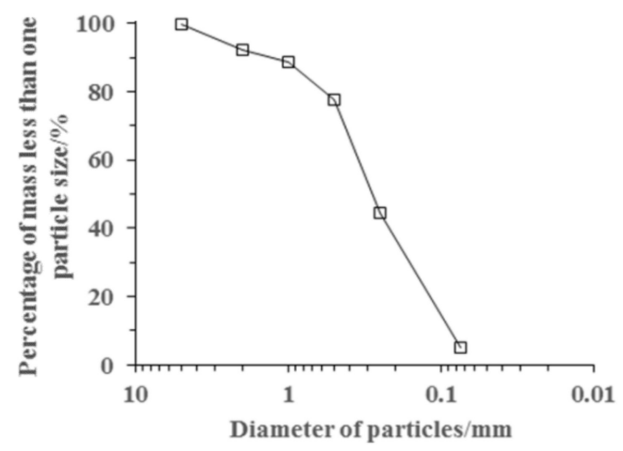

Figure 2. Particle size distribution curve for fine-grained soil.

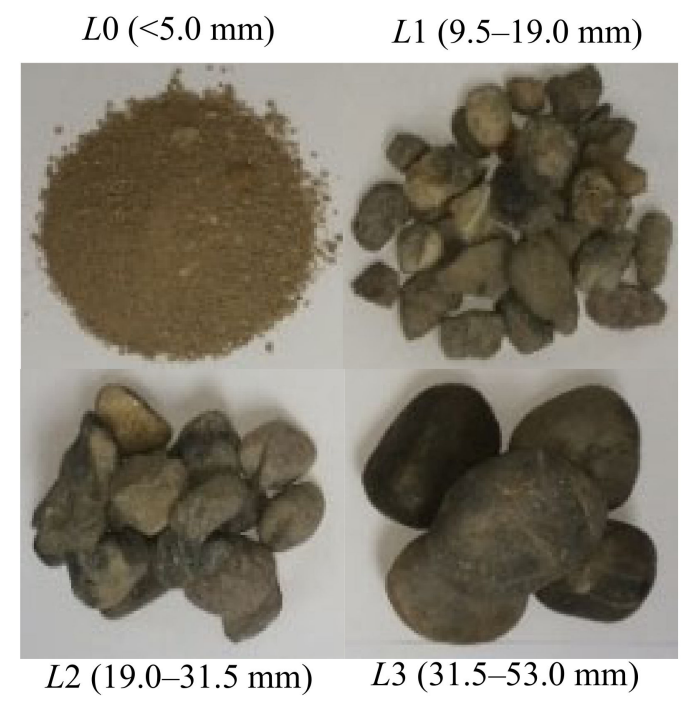

Figure 3. Soil-rock mixture (SRM) test materials.

\section{Methodology}

\subsection{Large-Sized Shear Test Apparatus}

Deformation tests were carried out by an SRM-1000 type large-sized geotechnical shear strength test apparatus made by Institute of Geology and Geophysics, Chinese Academy of Sciences, Beijing, China, which is one of few pieces of laboratory equipment controlled by a motor servo [62]. The advantage of this device is that the motor servo can achieve long-term creep loading. The equipment is composed of 
a hoisting system, servo loading system, shear box, measurement system, control system and a rolling shaft with low friction, as shown in Figure 4. The upper shear box is fixed to bear vertical loading, while the lower shear box can move to bear horizontal loading. The vertical force is applied to the stiff iron plate in the upper shear box to provide consolidation for the specimen. The upper box and lower box are connected by a dragging track to prevent the rotation of the upper box. The maximum shear plane clearance of the shear box is $30 \mathrm{~mm}$. The maximum vertical and horizontal loadings are $1000 \mathrm{kN}$. The resolution of the loading is $0.34 \mathrm{kN}$ in the vertical and horizontal directions. The maximum loading rate of the loading system is $4.0 \mathrm{~mm} / \mathrm{min}$. The maximum shear displacement is 100, with an accuracy of $0.05 \mathrm{~mm}$. The shear box is 300 in length, $300 \mathrm{in}$ width, and $300 \mathrm{~mm}$ in height. The maximum particle size (d) of the artificial SRM is determined based on the minimum dimension of the specimen (D); the relationship D/d $=6$ was proposed by Marsal [63]. Thus, considering the size effect of the particles, the maximum grain size of the block stone in group $L 3$ was approximately $1 / 6$ of the shear box size.

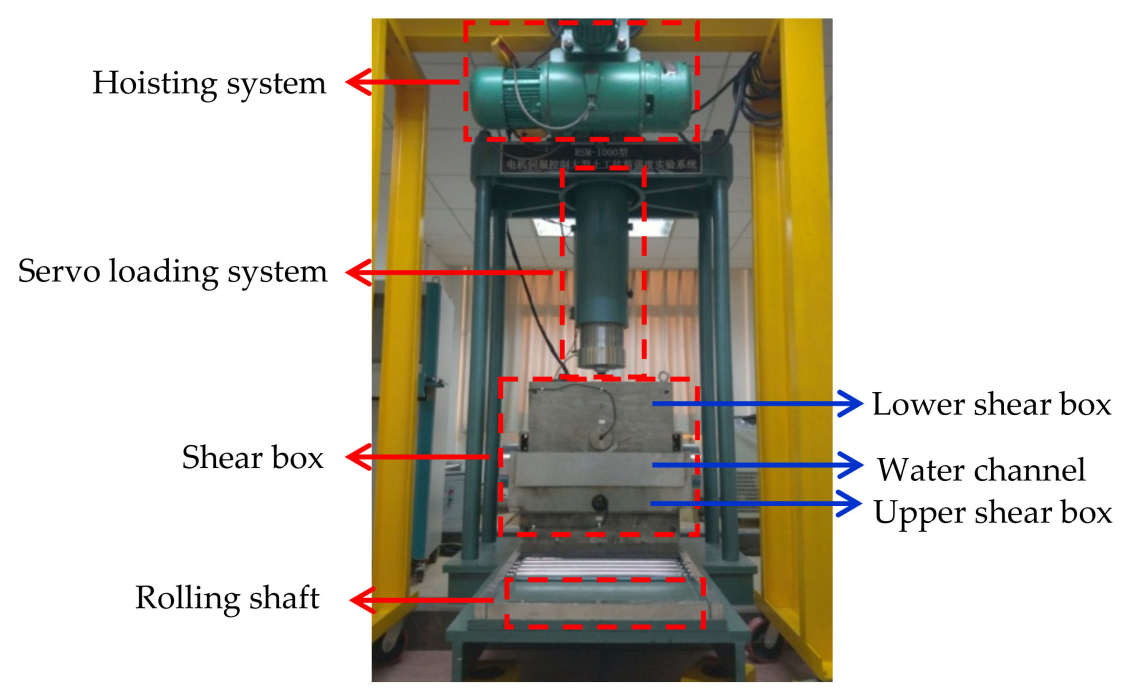

Figure 4. SRM-1000 large-sized geotechnical shear strength test apparatus controlled by a motor servo.

\subsection{Test Design}

The SRM specimens were prepared under the same water content, considering three factors: The stone content by mass $(0 \%, 30 \%, 50 \%$, and $70 \%)$, stone size $(L 1, L 2$, and $L 3)$, and overlying vertical pressure $(50,100,200,300$, and $400 \mathrm{kPa})$. The density of the specimens was $1.8 \mathrm{~g} / \mathrm{cm}^{3}$, and the water content of the clay soil was $5 \%$. The specimens were unsaturated. The pore water was connected with air. Thus, the suctions of samples were neglected. The block stones were randomly distributed in the sample. The shear plane clearance of the shear box was $15 \mathrm{~mm}$, which is between $1 / 3 \mathrm{~d}_{\max }$ and $1 / 4 \mathrm{~d}_{\max }$, based on the Chinese standard [64].

\subsection{Shear Deformation Monitoring Method}

The high heterogeneity of SRM produces deformation characteristics of the shear zone during the shear process that differs from those of soil [65]. Soft aluminum (Al) wires with diameters of $1.0 \mathrm{~mm}$ were inserted in holes with diameters of $5.0 \mathrm{~mm}$, which were drilled from the top of the upper sample to the bottom of the sample (Figure 5). The gaps around the $\mathrm{Al}$ wires were filled with dry ash. The $\mathrm{Al}$ wires are extremely soft, fine, and cannot withstand resistance. Thus, deformation of the $\mathrm{Al}$ wires can correspond to shear plane slipping. Therefore, they can be used to realize the slippage characteristics of stone particles, the deformation of shear zone slip, and its evolution law under the condition of a closed shear box. The three groups of $\mathrm{Al}$ wires were denoted as \#1, \#2, and \#3, in turn (Figure 5b). 


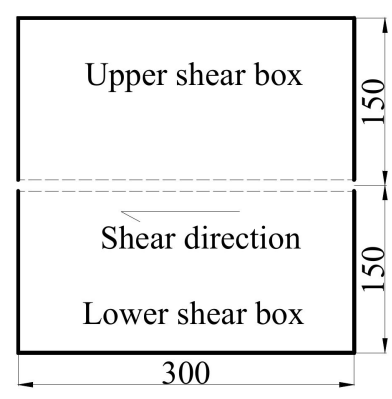

(a)

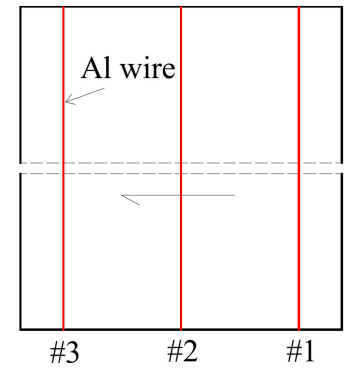

(c)

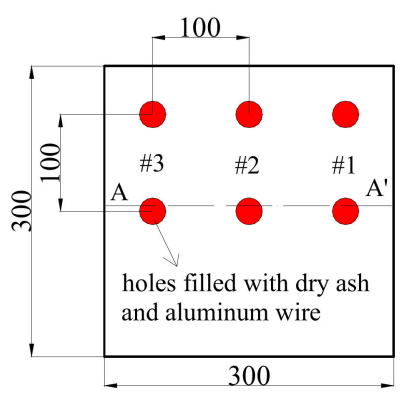

(b)

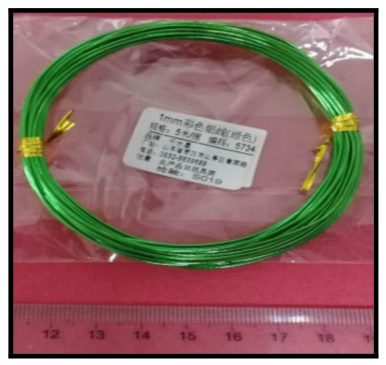

(d)

Figure 5. Schematic of the installation of Al wires. (a) Front view of the shear box (mm); (b) the top surface of the shear box $(\mathrm{mm})$; (c) profile map of $\mathrm{AA}^{\prime}$ in $(\mathbf{b})$; (d) aluminum (Al) wires with a diameter of $1.0 \mathrm{~mm}$.

\subsection{Test Procedure}

Step 1: Sample preparation. According to the design parameters of the tests, a certain amount of stones (e.g., the $L 1$ group and stone content of $30 \%$ ) and clay soil with water content of $5 \%$ were evenly mixed and sealed for $24 \mathrm{~h}$, following the Chinese standard [64].

Step 2: Sample consolidation. SRM samples were divided into three layers to fill the box in order to produce a relatively uniform stone distribution. The sample surface of each layer was scraped to ensure the upper and lower layers were tightly bonded. The sample was then consolidated to reach stability until the vertical deformation was less than $1.0 \mathrm{~mm} / \mathrm{h}$ to distinguish the amount of shear shrinkage deformation.

Step 3: Sample shearing. After consolidation, holes with diameters of $5.0 \mathrm{~mm}$ were drilled from the sample surface to bottom through the upper pressure plate by the rebar with the diameter of $5 \mathrm{~mm}$, despite the presence of large stones in specimens with large stone content. Then, soft Al wires with diameters of $1.0 \mathrm{~mm}$ were inserted into the holes, and the gaps around the $\mathrm{Al}$ wires were filled with dry ash, which was carefully compacted by hard wire to ensure the close contact and a coupled coherent deformation between dry ash, wire, and soil. We can consider the role of wire and ash compaction as marginal. The lower shear box moved along the shear plane with a shear rate of $0.4 \mathrm{~mm} / \mathrm{min}$ according to the Chinese standard [58]. The maximum shear displacement was approximately $6 \mathrm{~cm}$, or $20 \%$ of the sample size.

Step 4: Measurement. After shearing, the SRM specimen was excavated along profile AA' (Figure 5b). The vertical section was used to observe and measure the deformation of the $\mathrm{Al}$ wires, as shown in Figure 6. A visible shear deformation zone can be seen within the dashed box rather than a shearing gap. The possibility to excavate the samples along a vertical face in Figure 6 is a clear evidence of the strengthening effects of the negative pore water pressures from the silt sand. 


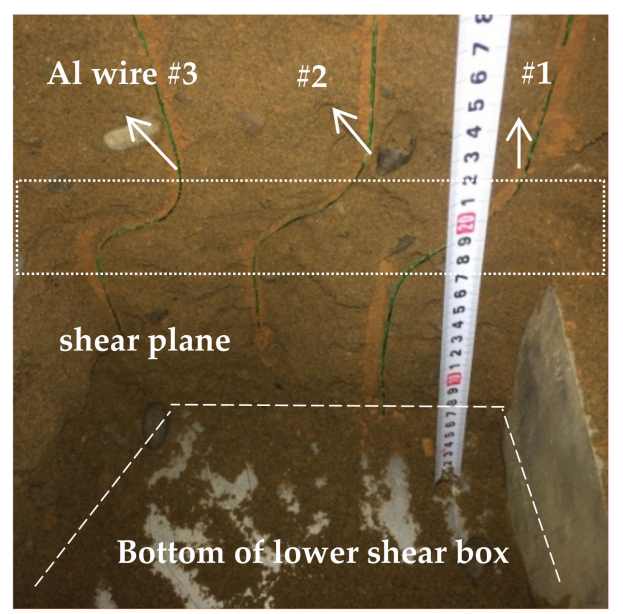

Figure 6. $\mathrm{AA}^{\prime}$ profile with deformation of the $\mathrm{Al}$ wires after shearing.

\section{Results}

The deformation of the $\mathrm{Al}$ wires reflects the relative motion characteristics of the block stones. Based on the deformation characteristics of the $\mathrm{Al}$ wires, the shear zone, and key shear zone in this test are defined, as shown in Figure 7. The shear zone is defined as the maximum impact range of soil-rock grain orientation sliding due to shearing rupture near the shear plane. The value is equal to the vertical distance, $d$, between points $\mathrm{A}$ and $\mathrm{D}$, which correspond to the bending points of the $\mathrm{Al}$ wires. The shear zone describes the whole region disturbed by shear action near the shear plane. The key shear zone is defined as the major impact range of soil-rock grain squeezing, rolling, and crushing due to shear movement near the shear plane. The value is equal to the vertical distance, $d^{\prime}$, between points $\mathrm{B}$ and $\mathrm{C}$, which are the junctions between the $\mathrm{Al}$ wire and the hole wall. The key shear zone describes the landslide slip-influenced zone [66] of stone squeezing and crushing due to shear slip near the landslide zone. The thickness of the shear zone and key shear zone in these tests are given in Table 2. The thickness of the key shear zone, $d^{\prime}$, ranged from 3.5 to $7.7 \mathrm{~cm}$. The specific value of $d^{\prime}$ and the distance from the bending point to the bottom of the box were between $18.0 \%$ and $30.0 \%$. According to the key shear zone and shear zone values, the movement ranges of the stones were less than $1 / 3$ the height of the shear box. Therefore, the boundaries would not limit the movement of the block stones. The height of the prepared SRM specimens could be decreased appropriately to reduce the workload of the large-sized direct shear tests, not considering the size effect of the particles. The specific values of the landslide zone and sliding body thickness were less than $30 \%$ for the non-rock landslides in Table 1. The change in thickness of the landslide slip zone depends on the topography, lithological characteristics, hydrological conditions, and composition of the slip zone. These test results are valuable references for predicting the shear zone thickness and evolution in non-rock landslides. 


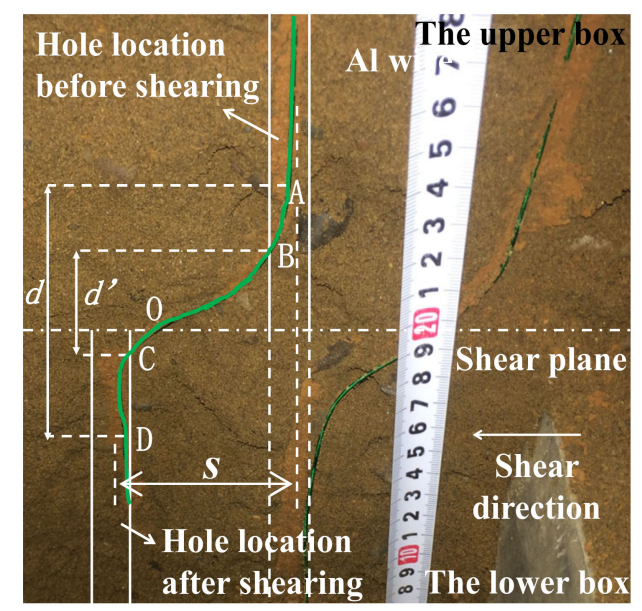

Figure 7. Deformation characteristics and parameters of the shear zone.

Table 2. Thickness of the key shear zone $\left(d^{\prime}\right)$ and shear zone $(d)$.

\begin{tabular}{|c|c|c|c|c|c|c|c|c|c|c|c|}
\hline \multirow{3}{*}{$\begin{array}{l}\text { Stone Size } \\
\quad(\mathrm{mm})\end{array}$} & \multirow{3}{*}{$\begin{array}{c}\text { Stone } \\
\text { Content } \\
(\%)\end{array}$} & \multicolumn{8}{|c|}{ Vertical Stress (kPa) } & \multicolumn{2}{|c|}{ Shear Strength } \\
\hline & & \multicolumn{2}{|c|}{50} & \multicolumn{2}{|c|}{200} & \multicolumn{2}{|c|}{300} & \multicolumn{2}{|c|}{400} & \multirow{2}{*}{$\begin{array}{c}c \\
(\mathrm{kPa})\end{array}$} & \multirow{2}{*}{$\varphi\left({ }^{\circ}\right)$} \\
\hline & & $d^{\prime}(\mathrm{cm})$ & $d(\mathrm{~cm})$ & $d^{\prime}(\mathrm{cm})$ & $d(\mathrm{~cm})$ & $d^{\prime}(\mathrm{cm})$ & $d(\mathrm{~cm})$ & $d^{\prime}(\mathrm{cm})$ & $d(\mathrm{~cm})$ & & \\
\hline$L 0(<5.0)$ & 0 & 3.9 & 5.1 & 4.3 & 5.5 & 3.5 & 4.6 & 3.7 & 5.0 & 33.3 & 17.9 \\
\hline \multirow{3}{*}{$\begin{array}{c}L 1 \\
(9.5-19.0)\end{array}$} & 30 & 4.7 & 6.2 & 5.4 & 7.1 & 5.6 & 7.5 & 4.5 & 6.2 & 13.0 & 24.7 \\
\hline & 50 & 6.1 & 6.8 & 6.4 & 7.9 & 6.8 & 9.1 & 5.2 & 6.6 & 15.3 & 33.4 \\
\hline & 70 & 5.5 & 7.3 & 6.4 & 8.6 & 5.2 & 7.3 & 6.1 & 9.4 & 31.5 & 37.9 \\
\hline \multirow{3}{*}{$\begin{array}{c}L 2 \\
(19.0-31.5)\end{array}$} & 30 & 4.3 & 6.1 & 5.7 & 7.2 & 5.3 & 6.5 & 5.5 & 7.0 & 15.0 & 28.7 \\
\hline & 50 & 6.3 & 7.9 & 7.2 & 9.1 & 6.5 & 8.3 & 6.9 & 8.8 & 16.6 & 35.0 \\
\hline & 70 & 6.1 & 7.5 & 6.7 & 8.5 & 6.1 & 8.3 & 6.6 & 7.7 & 25.2 & 41.0 \\
\hline \multirow{3}{*}{$\begin{array}{c}\text { L3 } \\
(31.5-53.0)\end{array}$} & 30 & 4.7 & 7.2 & 4.9 & 7.5 & 5.0 & 6.7 & 4.3 & 7.1 & 25.5 & 31.2 \\
\hline & 50 & 5.3 & 6.6 & 6.6 & 8.3 & 6.8 & 8.2 & 6.5 & 7.5 & 30.5 & 40.7 \\
\hline & 70 & 7.2 & 8.2 & 6.5 & 7.4 & 7.3 & 9.2 & 7.7 & 8.9 & 46.4 & 43.7 \\
\hline
\end{tabular}

\subsection{Analysis of the Deformation Characteristics of Al Wires}

Before the beginning of shearing, the sample first entered into a stage of compaction, as shown in Figure 8. Then, in the early stage of shearing, Al wires \#1 and \#3 exhibited deformation with the horizontal movement of the lower box to produce compressive deformation at both ends of the sample. At this time, $\mathrm{Al}$ wire $\# 2$ did not exhibit any horizontal bend as it was located in the relatively static middle part of the sample without movement (Figure 8b). SRM around the Al wire \#2 which was farther from the wall of the shear box, was pushed later in the absence of rigid support of the wall. In the late stage of shearing, $\mathrm{Al}$ wire \#2 gradually underwent deformation, while wires \#1 and \#3 continuously experienced deformation. Thus, the deformation of $\mathrm{Al}$ wires \#1 and \#3 occurred earlier than that of wire \#2 (Figure 8). The deformation value, s, of the Al wires is shown in Figure 9. The horizontal displacements of $\mathrm{Al}$ wires \#1 and \#3 at the ends of the box were clearly larger than the displacement of $\mathrm{Al}$ wire \#2 in the middle of the box (Figure 9).

The specimen can be considered as a unit in a slope. The upper box and the lower box can be compared to the sliding bed and sliding body, respectively. Shear failure occurred first at the front and back of the unit, after which shear deformation extended to the middle of the unit. This deformation pattern can be considered analogous to push-type shear deformation from back to front or composite shear deformation from the front and back to the middle of a slope. Based on the order in which the deformation of $\mathrm{Al}$ wires occurred, the cracks in the SRM at the top of the slope were caused by the active soil pressure, and the SRM gradually sank, compacted, and slid. Then, the SRM in the toe of the slope generated creep deformation. The SRM in the middle of slope finally generated shearing, rupturing, and the sliding surface gradually became damaged. The final shear plane was then broken, 
and the complete destruction of the slope occurred. Therefore, the failure mode of the SRM can be generalized as a process of gradual expansion and destruction caused by compaction at the top, creep at the toe, and then shearing rupture in the middle of the slope.

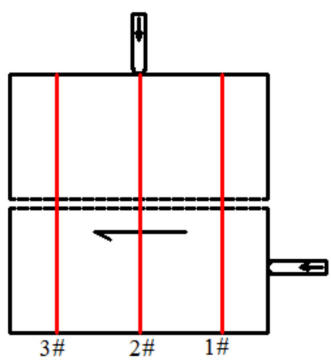

(a)

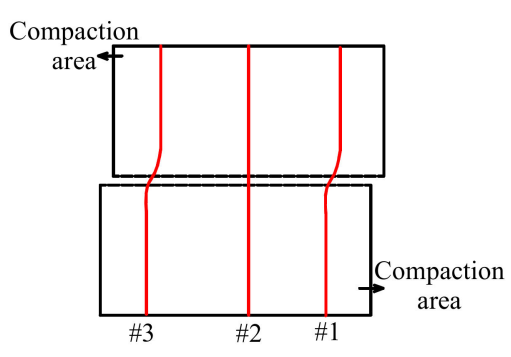

(b)

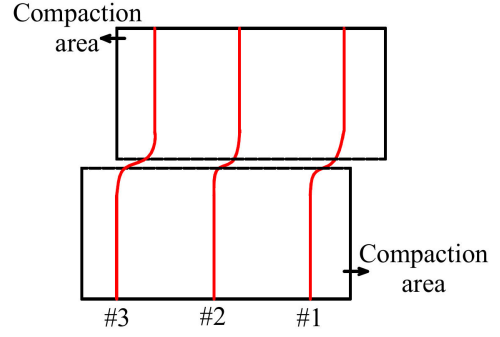

(c)

Figure 8. Schematic of the shearing process. (a) Beginning of shearing; (b) the early stage of shearing; (c) the late stage of shearing.

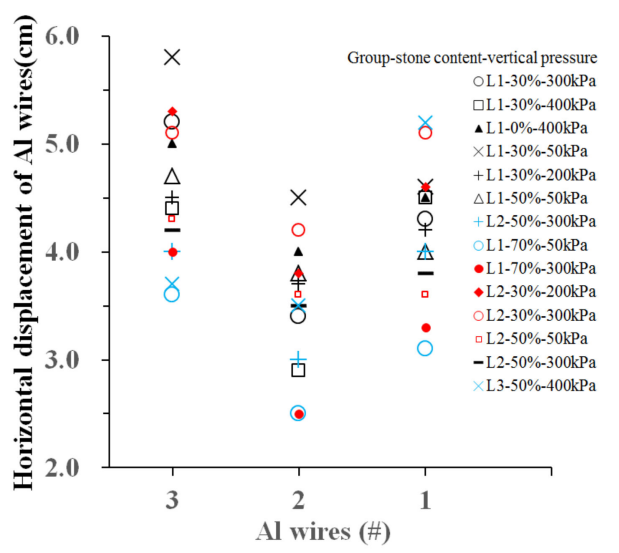

Figure 9. Horizontal displacement of $\mathrm{Al}$ wires.

\subsection{Analysis of Shear Deformation Characteristics}

For the specimen composed only of clay soil (group $L 0$, stone content $0 \%$ ), the $\mathrm{Al}$ wires became bent by the shear movement, and the deformation was smooth with an anti-s shape (Figure 10). With the stone content increasing, the deformation of the $\mathrm{Al}$ wires became overstretched from smooth curves to angular curves, and formation of the skeleton of the block stone was gradually revealed. At a stone content of $30 \%$ (Figures10b and 11a), the overall deformation of the Al wires was relatively smooth, and the region began to exhibit a faint angular deformation. In addition, the occlusion and effect of the skeleton of the block stones began to appear. When the stone content reached $50 \%$ (Figures $10 \mathrm{c}$ and $11 \mathrm{~b}$ ), the $\mathrm{Al}$ wires exhibited multiple bends and angular deformation, indicating a large-scale relative motion of the block stones, and the skeleton structure of SRM had been formed. With the granular size increasing, the angular deformation of the $\mathrm{Al}$ wires became more prominent, indicating that the occlusion of the large block stones was more obvious in the formation of the block structure (Figure 11b). The shear process was often accompanied by the sound of broken stones, which indicated that the turnover ability of the large rocks was weaker and the possibility of shear failure among the block stones was greater.

For stone content of $30 \%-50 \%$, there was a critical threshold for the stone content. When the stone content reached the critical threshold, the skeleton structure was formed in the sample. The deformation and strength of the specimen then began to be determined by the block stones. The larger the block stones were, the more obvious the block stones' occlusion was. In addition, the block stones underwent a tip cut or staggered redistribution. In this case, the shear failure mode of SRM was dominated by dilatancy deformation. Strictly speaking, when the stone content was just greater than the critical 
threshold, this sample material could be called SRM. When the stone content was less than the threshold $(30 \%)$, the stones had little effect on the deformation of the SRM, and the mechanical properties of the material could be treated as the soil. When the stone content reached $50 \%$, the formative stone skeleton structure had an obvious effect on the deformation, and the mechanical strength of the SRM was affected by both the stones and soil simultaneously. When the stone content reached $70 \%$, the aerial structure of the SRM had been formed. The deformation rules of the $\mathrm{Al}$ wires directly reflected the motion state and motion law of the block stones and fine-grained soil of the SRM. The stone content, stone size, and stone distribution directly affected the bending deformation of the $\mathrm{Al}$ wires, i.e., the degree of dispersion of the block stones around the $\mathrm{Al}$ wires affected the deformation of the $\mathrm{Al}$ wires. The more the block stones gathered, the greater the possibility of angular bending of the $\mathrm{Al}$ wires was [67].

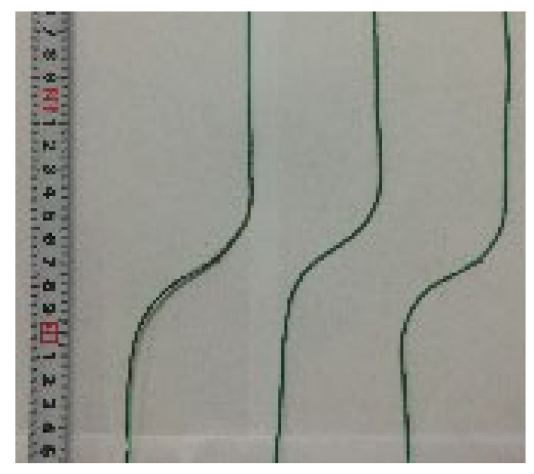

(a)

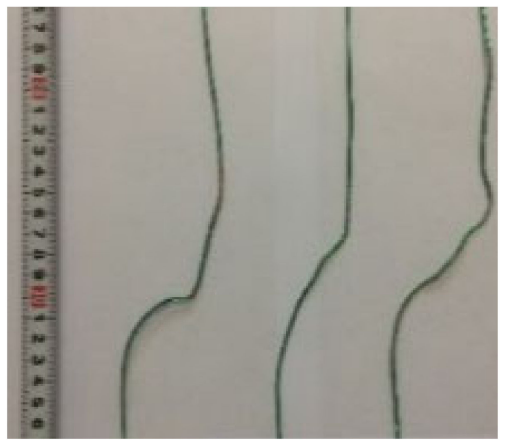

(c)

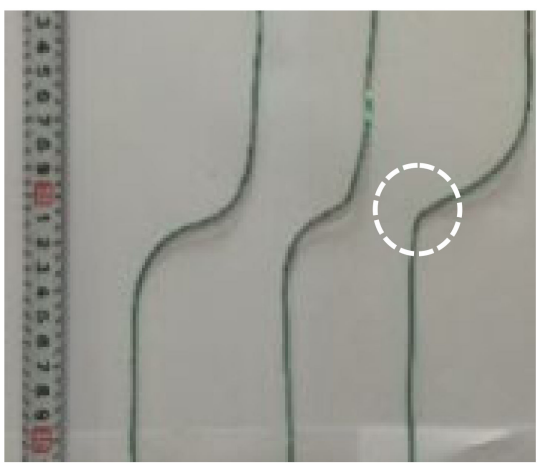

(b)

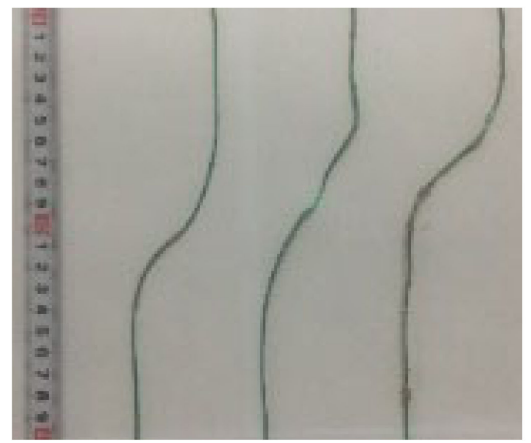

(d)

Figure 10. Deformation characteristics of $\mathrm{Al}$ wires in samples of group L1 with a vertical pressure of $400 \mathrm{kPa}$ and different stone contents. (a) Stone content $0 \%$; (b) stone content $30 \%$; (c) stone content $50 \%$; (d) stone content $70 \%$.

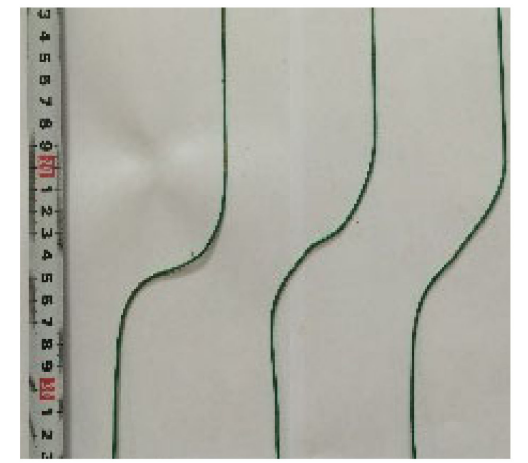

(a)

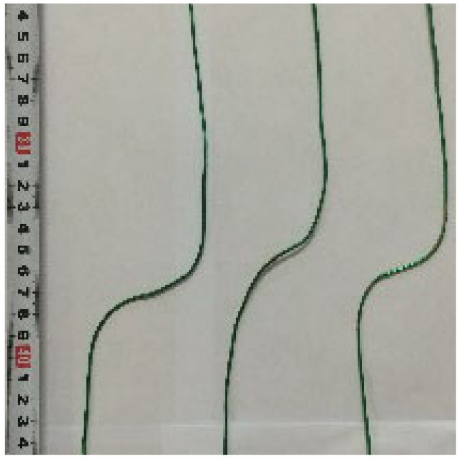

(b)

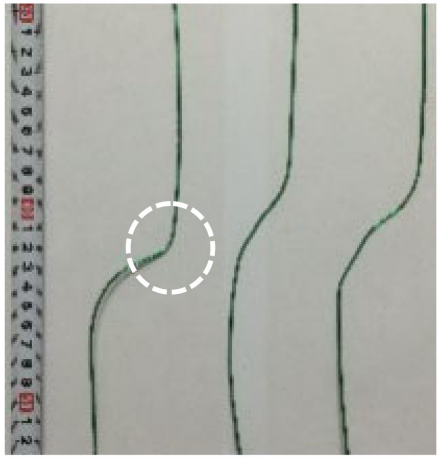

(c)

Figure 11. Cont. 


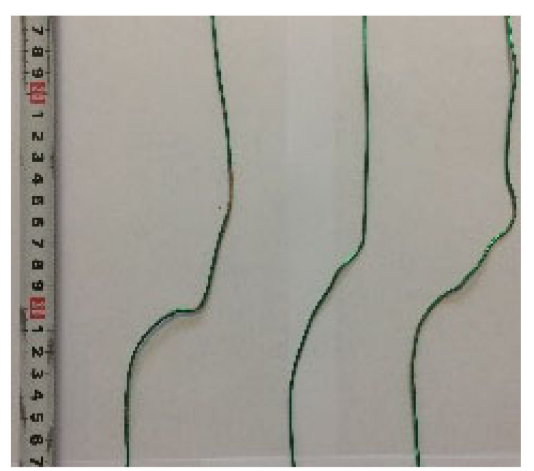

(d)

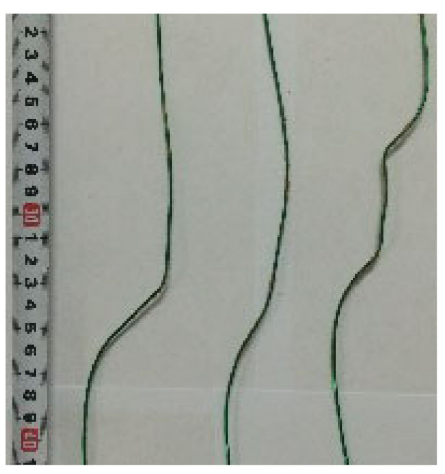

(e)

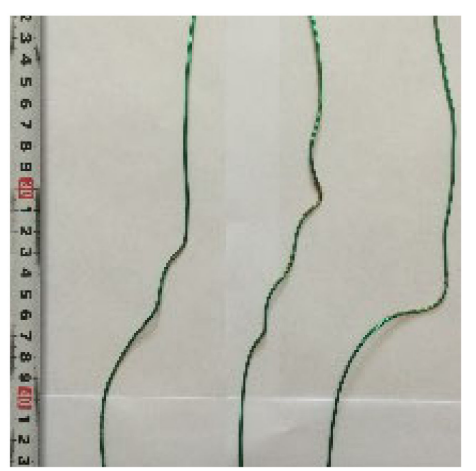

(f)

Figure 11. Comparison of the deformation characteristics of Al wires in samples after shear tests. (a) L1 stone size with a stone content of $30 \%$ and vertical pressure of $200 \mathrm{kPa}$; (b) L2 stone size with a stone content of $30 \%$ and vertical pressure of $200 \mathrm{kPa}$; (c) $L 3$ stone size with a stone content of $30 \%$ and vertical pressure of $200 \mathrm{kPa}$; (d) $L 1$ stone size with a stone content of $50 \%$ and vertical pressure of $400 \mathrm{kPa}$; (e) L2 stone size with a stone content of $50 \%$ and vertical pressure of $400 \mathrm{kPa}$; (f) L3 stone size with a stone content of $50 \%$ and vertical pressure of $400 \mathrm{kPa}$.

\subsection{Parameters of the Shear Strength}

The shear strength is the most important parameter for analyzing the stability of SRM slopes. The Mohr-Coulomb model was adopted to calculate the shear strength parameters of SRM in terms of total stresses, as shown in Table 2. All the vertical and horizontal stresses were average values. Four groups of vertical pressures and shear stresses for each test were calculated by linear fitting to obtain the friction angle and cohesion. Figure 12 gives the relationships between shear stress, vertical displacement, and horizontal displacement. The shear stresses of specimens with an $L 3$ stone content of $50 \%$ gradually increased with the horizontal displacement increasing. Furthermore, the specimens showed shear shrinkage characteristics, as shown in Figure 12a. At this point, the stones staggered each other and gradually compacted. The shear stresses of specimens with $L 3$ stone content of $70 \%$ gradually increased with the horizontal displacement increasing. However, the specimens showed the characteristic of first shrinking and then expanding, as shown in Figure 12b. At this point, due to more blocks, there was not enough space for compaction. Thus, with the increase of shear displacement, the block stone gradually occluded and climbed, and the dilatancy gradually increased. When the block stones staggered with each other, the shear stress suddenly decreased and shear shrinkage occurred. The friction angle increased linearly with the change of stone content for different stone sizes in the SRM specimens. The larger the stone size in the SRM was, the larger the friction angle of the specimen was, as shown in Figure 13a. This was mainly because the occlusal friction of the block increased with stone content and block size increasing. The cohesion was directly proportional to the change of the stone content for different stone sizes, as shown in Figure 13b. The cohesion of the specimens with block stones of the $L 3$ group was greater than that with stones of groups $L 1$ or $L 2$. For a sample with larger stone content, the shearing of grain itself was measured. This is the reason the larger values of cohesion were obtained. The cohesions of SRM depended on the unique fabric composed of pores, fine particles, and coarse particles with different spatial distribution and content. 


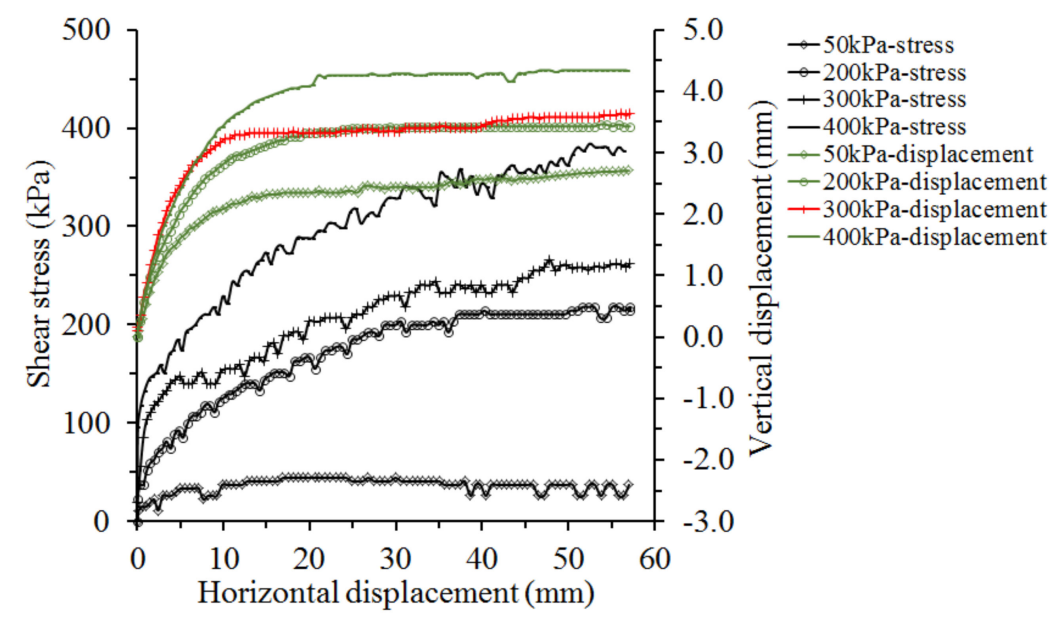

(a)

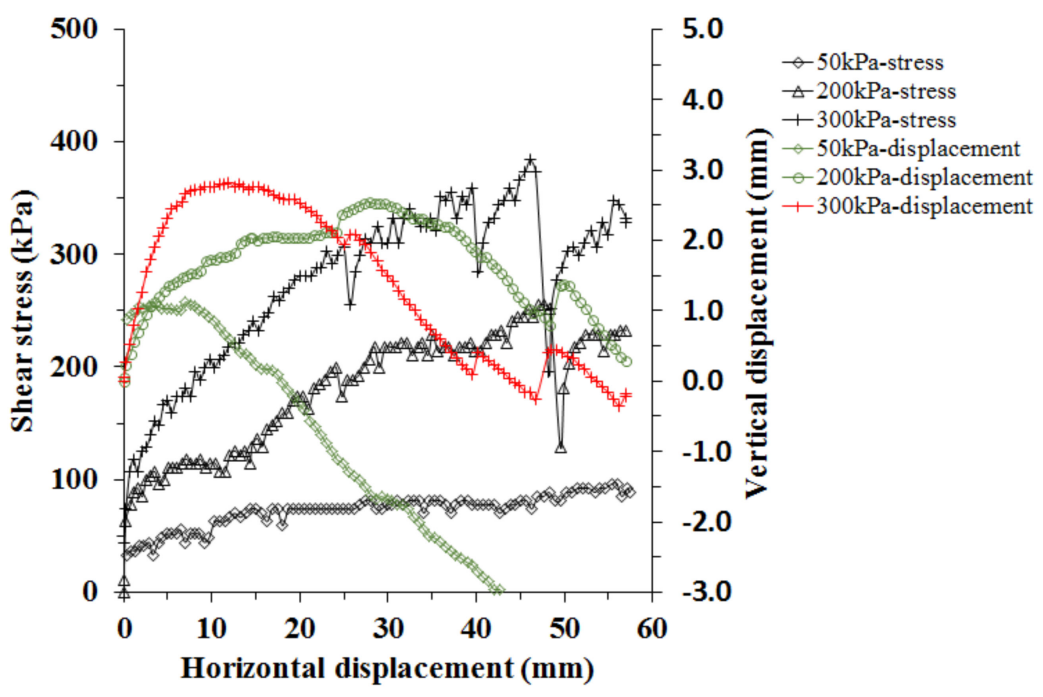

(b)

Figure 12. Shear stress and vertical displacement versus horizontal displacement. (a) L3 stone content of $50 \%$; (b) $L 3$ stone content of $70 \%$.

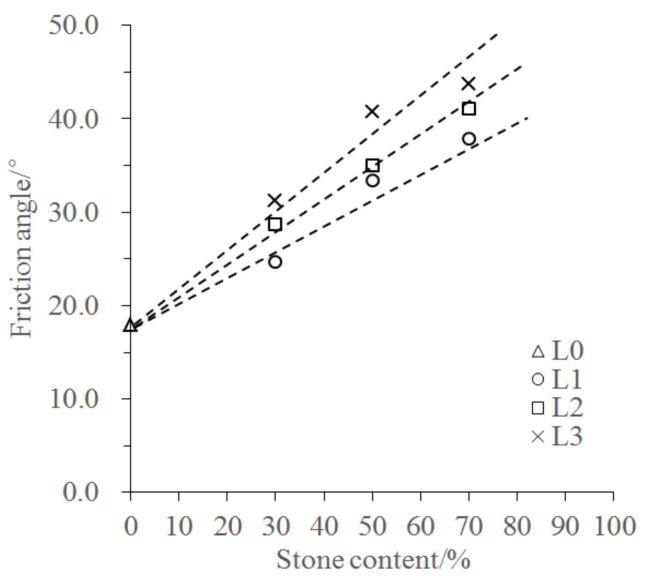

(a)

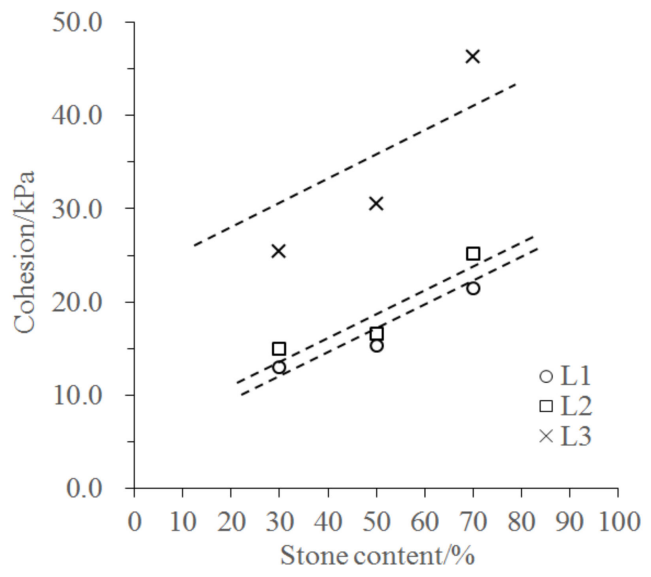

(b)

Figure 13. Parameters of shear strength versus the stone content of SRM. (a) Friction angle versus stone content; (b) cohesion versus stone content. 


\section{Discussion}

\subsection{Range Analysis of the Key Shear Zone Thickness}

The orthogonal test results in Table 2 were used to perform a range analysis. The levels of the three factors were listed in Table 3. Equation (1) [68] was used to calculate and analyze the primary and secondary relationships of the factors. The matrix $L_{16}\left(4^{3}\right)$ was used to analyze the key shear zone thickness, considering the three factors, $j$ (stone content, vertical pressure, and block stone size), and the four levels, $m(1,2,3,4)$, in Table 4 . The thickness of the key shear zone increased with the stone content increasing. The thickness of the key shear zone decreased with the vertical stress increasing. However, the thickness changed less with the block stone size increasing (Figure 14). The range values of the three factors, $j$, from largest to smallest were A > B > C (Table 4). The results indicated that the stone content had the greatest effect on the thickness of the key shear zone, with the vertical pressure second, and then the block stone size.

$$
R_{j}=\max \left(K_{j 1}, \bar{K}_{j 2}, \ldots, \bar{K}_{j m}\right)-\min \left(K_{j 1}, \bar{K}_{j 2}, \ldots, \bar{K}_{j m}\right)
$$

where $R_{j}$ is the range value of the column for factor $\mathrm{j}, K_{j m}$ is the UCS for factor $\mathrm{j}$ and level $\mathrm{m}$, and $\bar{K}_{j m}$ is the average UCS for factor $\mathrm{j}$ and level $\mathrm{m}$.

Table 3. Levels of factors for the range analysis.

\begin{tabular}{ccccc}
\hline \multirow{2}{*}{ Levels } & Factors & $\begin{array}{c}\text { Stone Content (\%) } \\
\text { A }\end{array}$ & $\begin{array}{c}\text { Vertical Pressure (kPa) } \\
\text { B }\end{array}$ & $\begin{array}{c}\text { Block Stone Size (mm) } \\
\text { C }\end{array}$ \\
\hline 1 & 0 & 50 & 0 \\
2 & 30 & 200 & $L 1(9.5-19.0)$ \\
3 & 50 & 300 & $L 2(19.0-31.5)$ \\
4 & 70 & 400 & $L 3(31.5-53.0)$ \\
\hline
\end{tabular}

Table 4. Range analysis of the key shear zone thickness.

\begin{tabular}{|c|c|c|c|c|}
\hline \multirow{2}{*}{ Number } & \multicolumn{3}{|c|}{ Factors } & \multirow{2}{*}{ Key Shear Zone Thickness (cm) } \\
\hline & A & B & $\mathrm{C}$ & \\
\hline 1 & $1(0)$ & $1(50)$ & $1(0)$ & 3.9 \\
\hline 2 & $1(0)$ & $2(200)$ & $2(L 1)$ & 4.3 \\
\hline 3 & $1(0)$ & $3(300)$ & $3(L 2)$ & 3.5 \\
\hline 4 & $1(0)$ & $4(400)$ & $4(L 3)$ & 3.7 \\
\hline 5 & $2(30)$ & $1(50)$ & $2(L 1)$ & 4.7 \\
\hline 6 & $2(30)$ & $2(200)$ & $1(0)$ & 4.3 \\
\hline 7 & $2(30)$ & $3(300)$ & $4(L 3)$ & 5.0 \\
\hline 8 & $2(30)$ & $4(400)$ & $3(L 2)$ & 5.5 \\
\hline 9 & $3(50)$ & $1(50)$ & $3(L 2)$ & 6.3 \\
\hline 10 & $3(50)$ & $2(200)$ & $4(L 3)$ & 6.6 \\
\hline 11 & $3(50)$ & $3(300)$ & $1(0)$ & 3.5 \\
\hline 12 & $3(50)$ & $4(400)$ & $2(L 1)$ & 5.2 \\
\hline 13 & $4(70)$ & $1(50)$ & $4(L 3)$ & 7.2 \\
\hline 14 & $4(70)$ & $2(200)$ & $3(L 2)$ & 6.7 \\
\hline 15 & $4(70)$ & $3(300)$ & $2(L 1)$ & 5.2 \\
\hline 16 & $4(70)$ & $4(400)$ & $1(0)$ & 3.7 \\
\hline ?K1 & 3.85 & 5.53 & 5.13 & \multirow{5}{*}{$\sum=79.3$} \\
\hline ?K2 & 4.88 & 5.48 & 4.85 & \\
\hline ?K3 & 5.40 & 4.30 & 5.50 & \\
\hline ?K4 & 5.70 & 4.53 & 5.63 & \\
\hline $\mathrm{R}_{\mathrm{j}}$ & 1.85 & 1.23 & 0.78 & \\
\hline
\end{tabular}




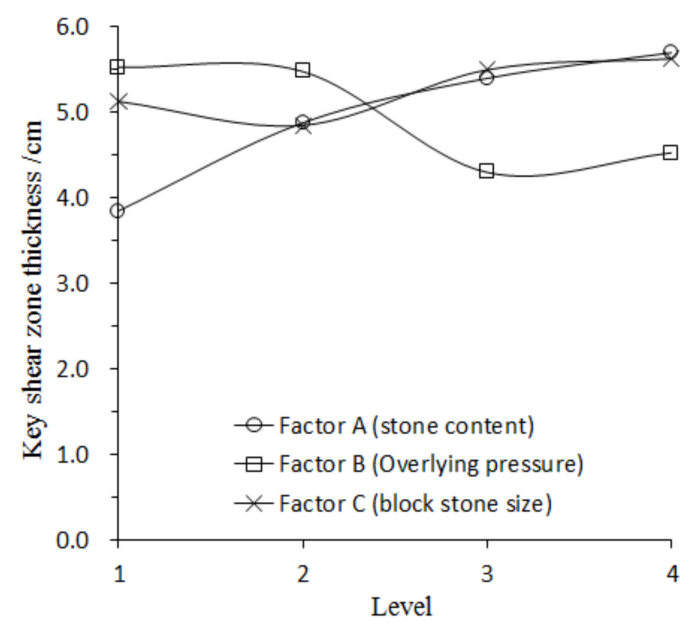

Figure 14. Relationship between the key shear zone thickness and the levels of different factors.

\subsection{Influence of Stone Content on the Key Shear Zone Thickness}

The key shear zone thickness initially increased and then decreased with the stone content increasing (Figure 15). The slope of the curves increased gradually, indicating that the increase in stone content enhanced the shear stiffness of the SRM to a certain extent. For the same block size, the interlocking effect of the block stone increased with stone content increasing. The "gear effect" of the block stone was gradually increased, and the key shear zone thickness increased. When the stone content was approximately 50\%, the thickness of the key shear zone reached a maximum, and the "gear effect" was most prominent. At this time, the block stones could produce slippage, drag, flipping, and interlocking (Figure 16). When the stone content reached approximately $70 \%$, the aerial structure of the block stones had formed in the sample. The fine-grained soil distributed among the stones was not dense. The stress state of a point contact was formed among the block stones. The relative motions of the block stones were characterized by the cutting of rock corners, stone crushing, or staggered redistribution. Therefore, the key shear zone thickness decreased accordingly.

In the vicinity of the shear plane, two types of block stones arrangements occurred: One was a single row throughout the shear surface, and the other was a double row (Figure 17a,d). The upper parts of the block stones were dyed black. In the shear process, the block stones were compacted and rolled with the slippage of the shear surface. The stones marked with black pigment have clearly been reversed, as shown in Figure 14b,c. In contrast, it was difficult to flip the block stones arranged in two rows. Instead, the shearing was mainly manifested as horizontal compaction and climbing movement among the stones along the interface between the upper sample and lower sample (Figure 17e,f). The fracture surface of the SRM formed along the stones surrounding the shear plane, i.e., the block stones produced a dilatancy effect. Thus, under the conditions of high stone content and large particle size (Figure 15c), the large stones near the shear plane had a dilatancy effect with shear sliding, resulting in an increase of the effect range of the shear zone. 


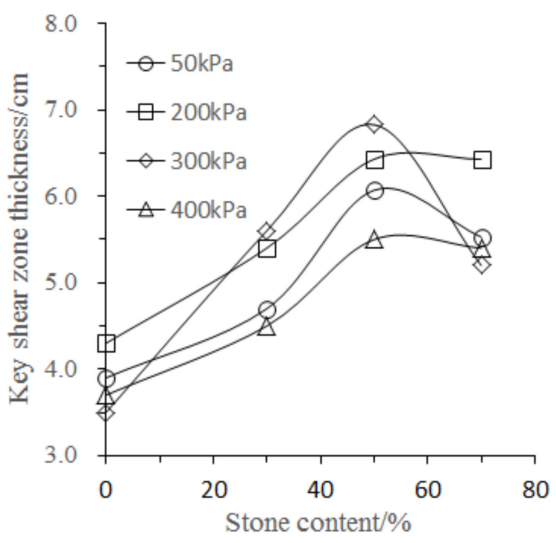

(a)

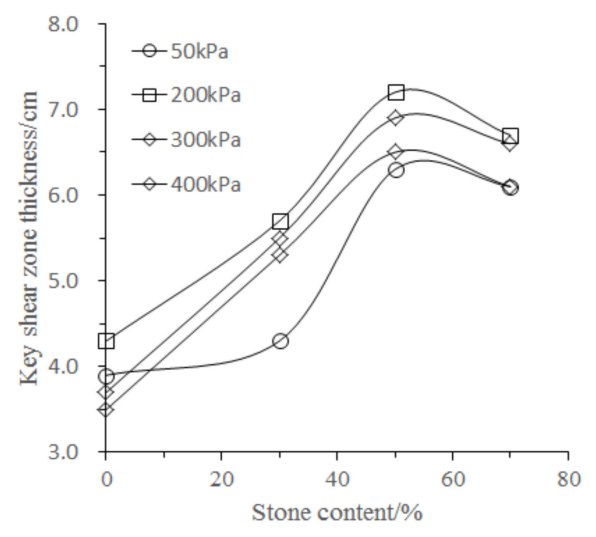

(b)

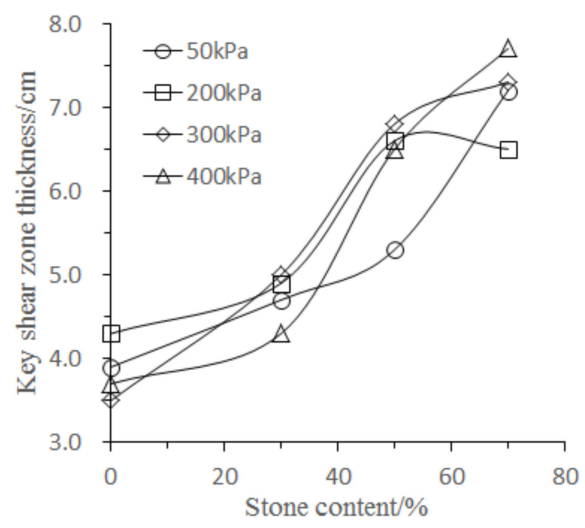

(c)

Figure 15. Effect of stone content on the key shear zone thickness. (a) Stone size L1; (b) stone size L2; (c) stone size $L 3$.

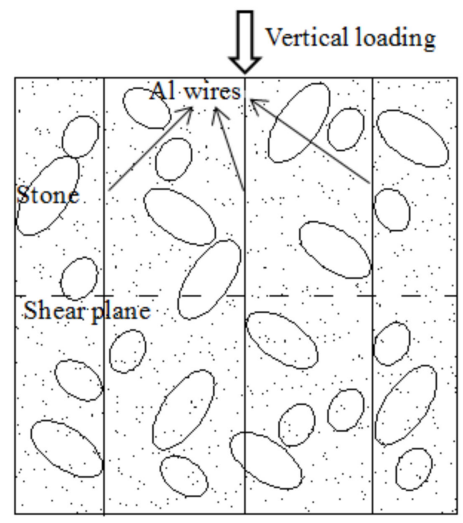

(a)

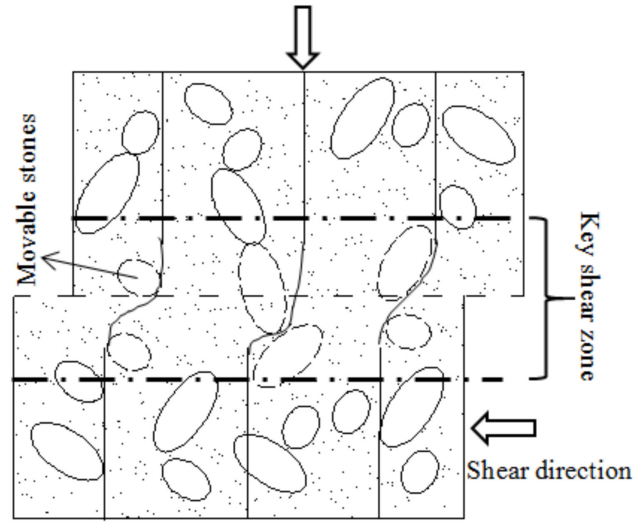

(b)

Figure 16. Schematic diagram of the movement state of block stones during shearing. (a) Before shearing; (b) after shearing. 


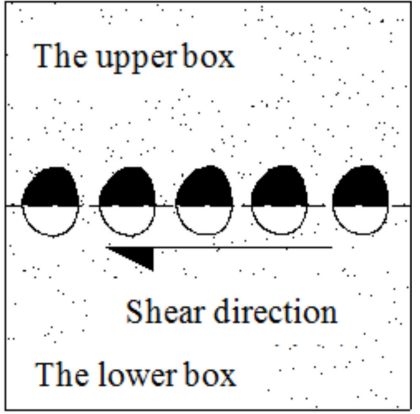

(a)

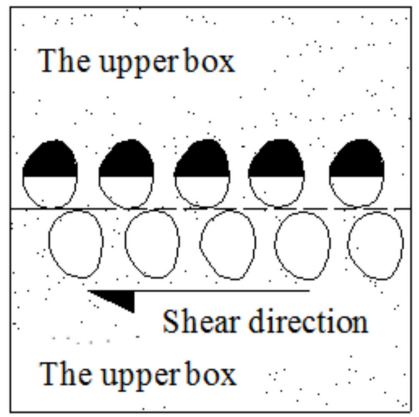

(d)

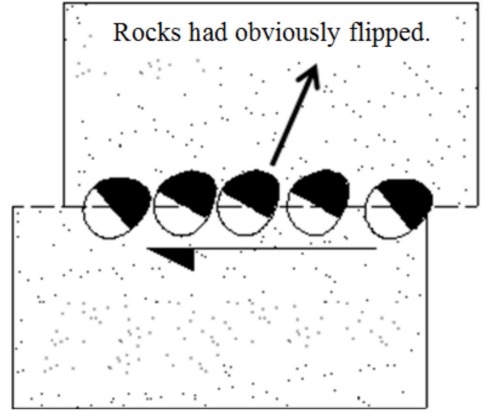

(b)

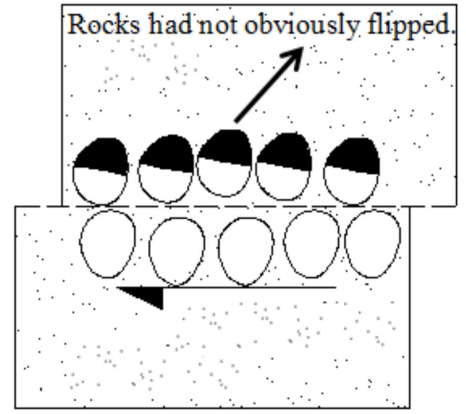

(e)

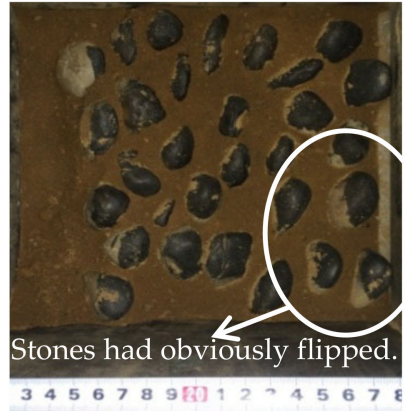

(c)

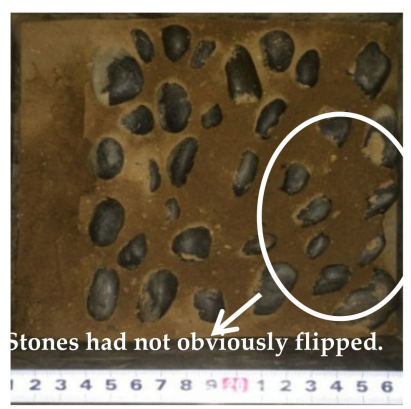

(f)

Figure 17. Deformation characteristics of block stones throughout the shear plane. (a) Single row of stones throughout shear plane, (b) location of these stones after shearing, (c) vertical view of the stones after shearing, (d) double row of stones throughout the shear plane, (e) location of these stones after shearing, (f) vertical view of the stones after shearing.

\subsection{Influence of Block Size on the Key Shear Zone Thickness}

At a stone content of $30 \%$, the block stones were suspended in the sample, and the shear deformation was mainly characterized by horizontal slipping. The thickness of the key shear zone was smaller, and the impact of the block size on the shear zone thickness was not obvious (Figure 18). For a sample with the same stone content, as the size of the block stone increased, the number of blocks decreased (Figure 19). The thickness of the shear zone was directly affected by the spatial distribution of block stones in the sample. The thickness of the shear zone of sample with stone content of $30 \%$ varied from 4 to $6 \mathrm{~cm}$. At a stone content of $50 \%$, the variation in the thickness of the key shear zone of the SRM with different particle sizes was decreased. The thickness of the shear zone of sample with stone content of $50 \%$ varied from 5 to $7 \mathrm{~cm}$. Under the condition of a high stone content $(70 \%)$, the thickness of the key shear zone increased with the block size increasing. The thickness of the shear zone of sample with stone content of $70 \%$ varied from 5 to $8 \mathrm{~cm}$. The main reason for this was that the large stones near the fracture plane would roll or swell with slippage of the shear plane, resulting in an increase of the range of the key shear zone. On one hand, there was a larger "gear effect" caused by the rolling of large stones penetrating the shear plane. On the other hand, the large stones on both sides of the shear plane climbed along the contact surface to produce a shear dilatancy effect.

The essential reason for the influence of the stone content and block size on the key shear zone thickness was the tightness degree of the block stone arrangement. With the stone content increasing, the "gear effect" among the block stones was enhanced, and the coarse particles squeezing each other gradually took the stress. The probability of the stones embedded with each other decreased with block size in samples increasing under the same stone content. The samples exhibited the characteristics of the concentrated distribution for large stones and dispersed distribution for small stones (Figure 19). Thus, the disorder degree of the block stones in SRM decreased with block size increasing under the same stone content. 


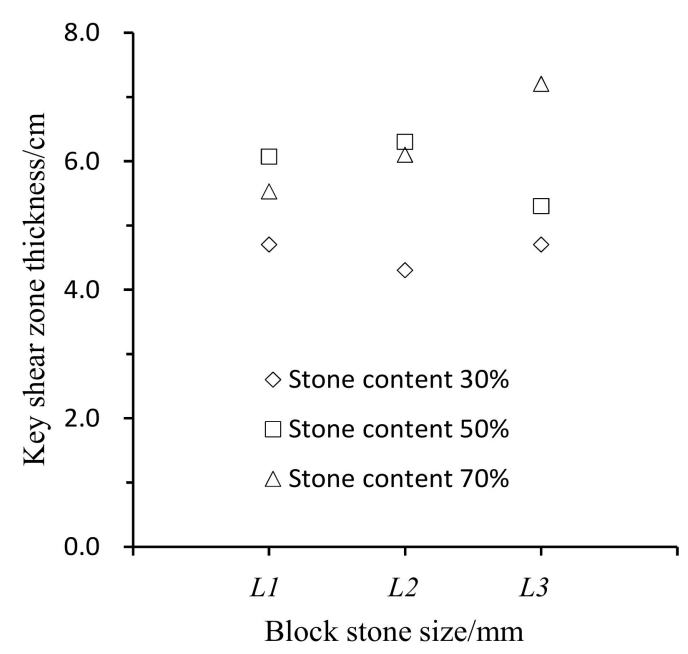

(a)

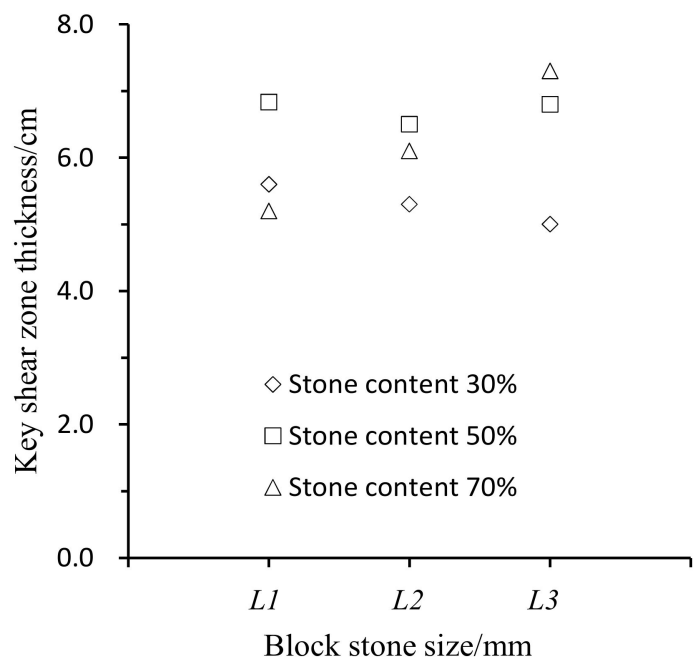

(c)

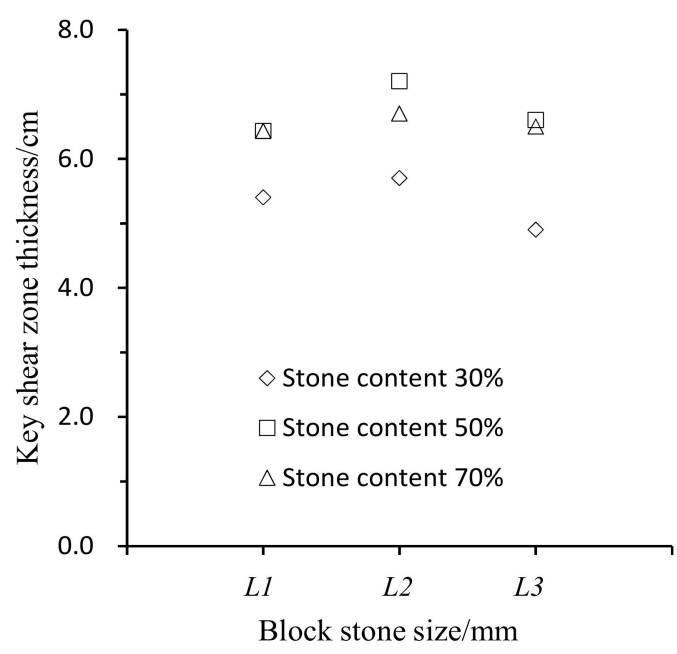

(b)

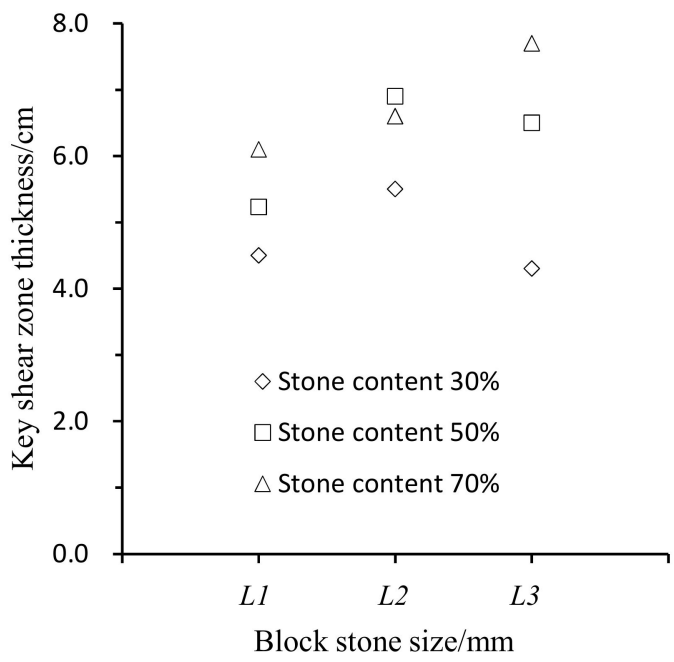

(d)

Figure 18. Variation in the key shear zone thickness with increasing stone sizes under different vertical pressures. (a) 50; (b) 200; (c) 300; (d) $400 \mathrm{kPa}$.

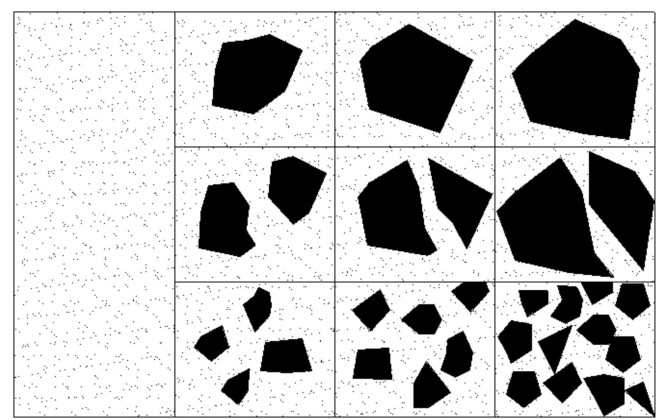

(a) (b)

(c)

(d)

Figure 19. Schematic drawing of the block stone size and distribution. (a) A state in which the strength is completely controlled by the soil; (b) a state in which the strength is mainly controlled by the soil; (c) a state in which the strength is controlled by the soil and stone; (d) a state in which the strength controlled by the stone. 


\subsection{Influence of Vertical Pressure on the Key Shear Zone Thickness}

The key shear zone thickness initially increased and then decreased with vertical stress increasing for different block sizes (Figure 20). Under the vertical pressures of 50 to $300 \mathrm{kPa}$, the movements of the block stones and fine particles were mainly rotation or expansion. The interaction of the block stones increased with vertical stress increasing. The "gear effect" of the SRM gradually became more prominent. As a result, the key shear zone thickness gradually increased. At vertical pressures of greater than $300 \mathrm{kPa}$, the improvement in the sample compactness directly increased the degree of embedding of the block stones in the vertical and horizontal directions in the SRM. There was insufficient energy for the block stones to swell along the stone interface under the greater vertical pressure. Thus, the movements of the block stones were mainly characterized by dislocation redistribution and corner cutting. The key shear zone thickness began to decrease (Figure 20a,b). With a higher stone content (70\%) and larger size (group L3), stone movement patterns of dislocation redistribution, corner cutting, and dilatancy coexisted (Figure 20c). Therefore, the change in the key shear zone thickness was closely related to the stone content, stone size, overburden pressure, and stone strength.

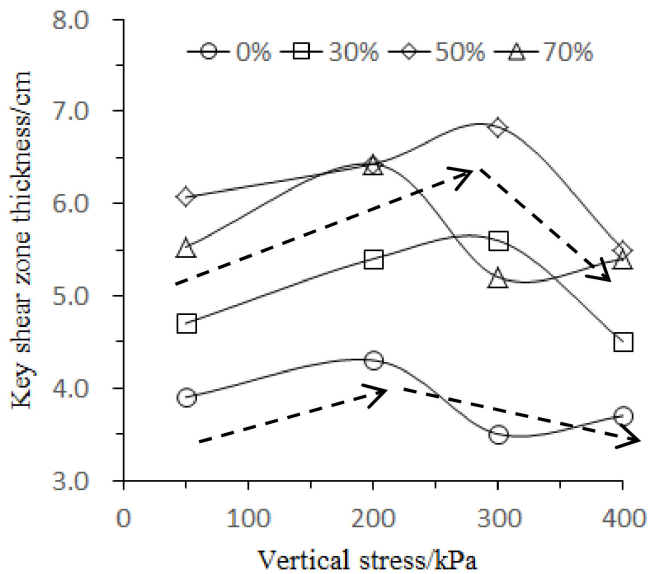

(a)

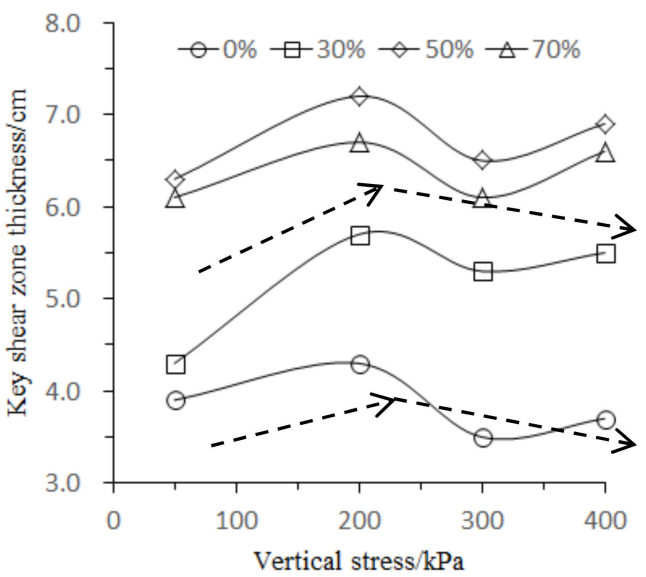

(b)

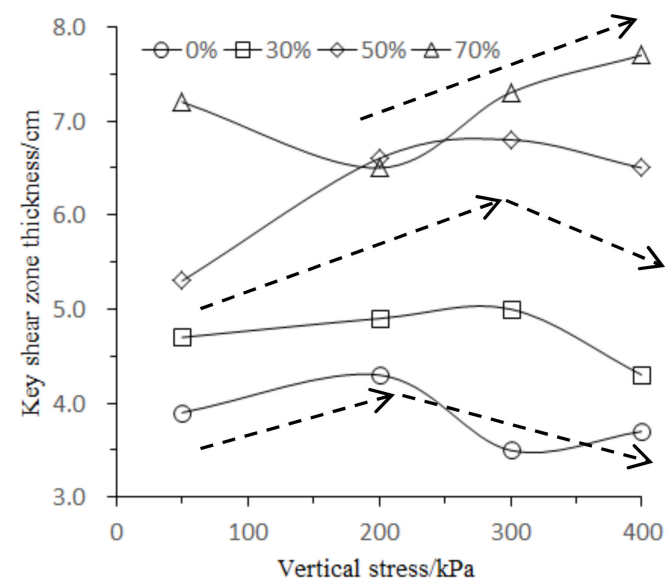

(c)

Figure 20. Variation in the key shear zone thickness with increasing vertical pressure for different stone sizes. (a) Stone size $L 1$; (b) stone size $L 2$; (c) stone size $L 3$.

\section{Conclusions}

This study focused on the shear deformation characteristics of SPM specimens, which are a special type of SRM, using a large-sized direct shear test apparatus and considering three main structural factors, namely the stone content, stone size, and vertical pressure. The main conclusions are as follows: 
1. The combination of $\mathrm{Al}$ wires and dry ash could be used to measure the deformation of the shear zone directly in large-sized direct shear tests of SRM;

2. The stone contents $30 \%$ and $70 \%$ were two critical thresholds to determine the deformation characteristics of SRM;

3. The stone content had the greatest effect on the thickness of the key shear zone; the vertical pressure was second, and then the block stone size;

4. Under the conditions of high stone content (70\%) and large particle size (group L3), the block stones distributed near the shear plane were dominated by dilatancy and generated extrusion, angular shear, and dislocation redistribution with changes in the shear deformation;

5. The failure mode of SRM could be generalized as a process of gradual expansion and destruction caused by compaction at the top, creep at the toe, and then shearing rupture in the middle of the slope;

6. The possibility to excavate the samples along a vertical face was clear evidence of the strengthening effects of the negative pore water pressures of samples.

Author Contributions: Conceptualization, Z.L.; data curation, Z.L. and F.H.; formal analysis, Z.L. and S.Q.; investigation, Z.L. and F.H.; methodology, Z.L. and R.H.; project administration, S.Q.; validation, Z.L.; writing-original draft, Z.L. and F.H.; writing-review and editing, Z.L., Y.Z., and Y.B. All authors have read and agreed to the published version of the manuscript.

Funding: This work was funded by the Second Tibetan Plateau Scientific Expedition and Research Program (STEP) (Grant No. 2019QZKK0904), National Natural Science Foundation of China (Grant No. 41672316), Youth Innovation Promotion Association CAS (Grant No. 2017092), Chinese Academy of Sciences Key Deployment Project (Grant No. KFZD-SW-422), the International Cooperation Program of Chinese Academy of Sciences (Grant No. 131551KYSB20180042), and the Science and Technology Project of Henan Provincial Department of Transportation (Grant No. 2017Z3).

Conflicts of Interest: The authors declare no conflict of interest.

\section{References}

1. You, X.H.; Tang, J.S. Research on horizonal push-shear in-situ test of soil and rock-mixture. Chin. J. Rock Mech. Eng. 2002, 21, 1537-1540.

2. Xia, J.W.; Guo, H.Z. Study on landslide distribution characteristics and main control factors in the upper Yangtze river. Hydrogeol. Eng. Geol. 1997, 1, 19-32.

3. Wen, B.P.; Aydin, A.; Aydin, N.S.D.; Li, Y.R.; Chen, H.Y.; Xiao, S.D. Residual strength of slip zones of large landslides in the Three Gorges area, China. Eng. Geol. 2007, 93, 82-98. [CrossRef]

4. Medley, E.; Goodman, R.E. Estimating the block volumetric proportion of melanges and similar block-in-matrix rocks (bimrocks). In Proceeding of the 1st North American Rock Mechanics Conference (NARMS), Austin, TX, USA, 20 February 1994; Balkema: Rotterdam, The Netherlands, 1994; pp. 851-858.

5. Indrawan, I.G.B.; Rahardjo, H.; Leong, E.C. Effects of coarse-grained materials on properties of residual soil. Eng. Geol. 2006, 82, 154-164. [CrossRef]

6. Rahardjo, H.; Indrawan, I.G.B.; Leong, E.C.; Yong, W.K. Effects of coarse-grained material on hydraulic properties and shear strength of top soil. Eng. Geol. 2008, 101, 165-173. [CrossRef]

7. Uday, K.V.; Padmakumar, G.P.; Singh, D.N. Some studies on morphology of the coarse-grained soils. Eng. Geol. 2013, 152, 48-55. [CrossRef]

8. Zhang, L.H.; Ma, W.; Yang, C.S.; Yuan, C. Investigation of the pore water pressures of coarse-grained sandy soil during open-system step-freezing and thawing tests. Eng. Geol. 2014, 181, 233-248. [CrossRef]

9. Sundell, J.; Rosén, L.; Norberg, T.; Haaf, E. A probabilistic approach to soil layer and bedrock-level modeling for risk assessment of groundwater drawdown induced land subsidence. Eng. Geol. 2016, 203, 126-139. [CrossRef]

10. Macaulay, D.B.; Bouazza, A.; Singh, R.M.; Wang, B.; Ranjith, P.G. Thermal conductivity of soils and rocks from the Melbourne (Australia) region. Eng. Geol. 2017, 164, 131-138. [CrossRef]

11. Rocchia, I.; Coopb, M.R.; Maccarini, M. The effects of weathering on the physical and mechanical properties of igneous and metamorphic saprolites. Eng. Geol. 2017, 231, 56-67. [CrossRef] 
12. Vallejo, L.E.; Mawby, R. Porosity influence on the shear strength of granular material-clay mixtures. Eng. Geol. 2000, 58, 125-136. [CrossRef]

13. Wu, P.K.; Matsushima, K.; Tatsuoka, F. Effects of specimen size and someother factors on the strength and deformation of granular soil in direct sheartests. ASTM Geotech. Test. J. 2008, 31, 45-64.

14. Xiao, J.H.; Luo, Z.; Martin, J.R., II; Gong, W.P.; Wang, L. Probabilistic geotechnical analysis of energy piles in granular soils. Eng. Geol. 2016, 209, 119-127. [CrossRef]

15. Hu, W.; Scaringi, G.; Xu, Q.; Pei, Z.; Van-Asch, W.J.; Hicher, P.Y. Sensitivity of the initiation and runout of flowslides in loose granular deposits to the content of small particles: An insight from flume tests. Eng. Geol. 2017, 231, 34-44. [CrossRef]

16. Pegah, E.; Liu, H.B.; Dastanboo, N. Evaluation of the lateral earth pressure coefficients at-rest in granular soil deposits using the anisotropic components of S-wave velocity. Eng. Geol. 2017, 230, 55-63. [CrossRef]

17. Sun, Y.F.; Xiao, Y. Fractional order plasticity model for granular soils subjected to monotonic triaxial compression. Int. J. Solids Struct. 2017, 118-119, 224-234. [CrossRef]

18. Chang, W.J.; Phantachang, T. Effects of gravel content on shear resistance of gravelly soils. Eng. Geol. 2016, 207, 78-90. [CrossRef]

19. Dong, H.; Huang, R.Q.; Gao, Q.F. Rainfall infiltration performance and its relation to mesoscopic structural properties of a gravelly soil slope. Eng. Geol. 2017, 230, 1-10. [CrossRef]

20. Kokusho, T.; Hara, T.; Hiraoka, R. Undrained shear strength of granular soils with different particle gradations. J. Geotech. Geoenviron. Eng. 2004, 130, 621-629. [CrossRef]

21. Chen, H.; Wan, J.P. The effect of orientation and shape distribution of gravel on slope angles in central Taiwan. Eng. Geol. 2004, 72, 19-31. [CrossRef]

22. Zhou, Z.; Fu, H.L.; Liu, B.C. Experimental study of the permeability of soil-rock-mixture. J. Hunan Univ. Nat. Sci. 2006, 33, 25-28.

23. Wang, X. Research on Influence Factors of Mechanics Characteristics and Failure Mechanism of Soil-Rock Mixture. Master's Thesis, Yangtze River Scientific Research Institute, Wuhan, China, 2010.

24. Holtz, W.G.; Lowitz, C.W. Compaction Characteristics of Gravelly Soils. Spec. Tech. Publ. ASTM 1957, 232, 70-83.

25. Patwardhan, A.S.; Rao, J.S.; Gaidhane, R.B. Interlocking effects and shearing resistance of boulders and large size particles in a matrix of fines on the basis of large scale direct shear tests. In Proceedings of the 2nd Southeast Asian Conference on Soil Mechanics, Singapore, 15 May 1970; pp. 265-273.

26. Vallejo, L.E.; Zhou, Y. The mechanical properties of simulated soil-rock mixtures. In Proceedings of the 13th International Conference on Soil Mechanics and Foundations Engineering, New Delhi, India, 5-10 January 1994; pp. 365-368.

27. Casagli, N.; Ermini, L.; Rosati, G. Determining grain size distribution of the material composing landslide dams in the Northern Apennines: Sampling and processing methods. Eng. Geol. 2003, 69, 83-97. [CrossRef]

28. Enomoto, T.; Qureshi, O.H.; Sato, T.; Koseki, J. Strength and deformation characteristics and small strain properties of undisturbed gravelly soils. Soils Found. 2013, 53, 951-965. [CrossRef]

29. Li, C.S.; Zhang, D.; Wang, H.X. 3D mesh generation for soil-rock mixture based CT scanning. Rock Soil Mech. 2014, 35, 2731-2736.

30. Zhang, S.; Tang, H.M.; Zhan, H.B.; Lei, G.P.; Cheng, H. Investigation of scale effect of numerical unconfined compression strengths of virtual colluvial-deluvial soil-rock mixture. Int. J. Rock Mech. Min. Sci. 2015, 77, 208-219. [CrossRef]

31. Wang, Y.; Li, X.; Zheng, B. Stress-strain behavior of soil-rock mixture at medium strain rates-Response to seismic dynamic loading. Soil Dyn. Earthq. Eng. 2017, 93, 7-17. [CrossRef]

32. Li, X.R. Experimental Study on Deformation Characteristics of Earth-Rock Aggregate. Master's Thesis, Dalian University of Technology, Dalian, China, 2012.

33. Zhang, Z.L.; Xu, W.J.; Xia, W.; Zhang, H.Y. Large-scale in-situ test for mechanical characterization of soilrock mixture used in an embankment dam. Int. J. Rock Mech. Min. Sci. 2016, 86, 317-322. [CrossRef]

34. Simoni, A.; Houlsby, G.T. The direct shear strength and dilatancy of sand-gravel mixtures. Geotech. Geol. Eng. 2006, 24, 523-549. [CrossRef]

35. Khalkhali, A.B.; Mirghasemi, A.A. Numerical and experimental direct shear tests for coarse-grained soils. Particuology 2009, 7, 83-91. [CrossRef] 
36. Zhou, Q.; Shen, H.H.; Helenbrook, B.T.; Zhang, H.W. Scale dependence of direct shear tests. Chin. Sci. Bull. 2009, 54, 4337-4348. [CrossRef]

37. Fu, W.X.; Zheng, X.; Lei, X.Z.; Deng, J.H. Using a modified direct shear apparatus to explore gap and size effects on shear resistance of coarse-grained soil. Particuology 2015, 23, 82-89. [CrossRef]

38. Coli, N.; Berry, P.; Boldini, D. In situ non-conventional shear tests for the mechanical characteristics of a bimrock (BimTest). Int. J. Rock Mech. Min. Sci. 2011, 48, 95-102. [CrossRef]

39. Xu, W.J.; Xu, Q.; Hu, R.L. Study on the shear strength of Soil-rock mixture by large scale direct shear test. Int. J. Rock Mech. Min. Sci. 2011, 48, 1235-1247.

40. Miller, E.A.; Sowers, G.F. The strength characteristics of soil-aggregate mixture. Highw. Res. Board Bull. 1957, $183,16-23$.

41. Cook, B.D. The effect of stone content, size, and shape on the engineering properties of a compacted silty clay. Bull. Assoc. Eng. Geol. 1990, 27, 245-253.

42. Tian, H.N.; Jiao, Y.Y.; Wang, H. Research on biaxial test of mechanical characteristics on soil-rock aggregate (SRA) based on particle flow code simulation. Chin. J. Rock Mech. Eng. 2015, 34, 3564-3573.

43. Wang, J.; Dove, J.E.; Gutierrez, M.S. Discrete-continuum analysis of shear banding in the direct shear test. Géotechnique 2007, 57, 513-526. [CrossRef]

44. Ding, X.L.; Li, Y.; Wang, X. Particle flow modeling mechanical properties of soil and rock mixtures based on digital image. Chin. J. Rock Mech. Eng. 2010, 29, 487-494.

45. Jia, X.M.; Chai, H.J.; Zheng, Y.R. Mesomechanics research of large direct shear test on soil and rock aggregate mixture with particle flow code simulation. Rock Soil Mech. 2010, 31, 2695-2703.

46. Potts, D.M.; Dounias, G.T.; Vaughan, P.R. Finite element analysis of the direct shear box test. Geotechnique 1987, 37, 11-23. [CrossRef]

47. Xu, W.J.; Yue, Z.Q.; Hu, R.L. Study on the mesostructure and mesomechanical characteristics of the soil-rock mixture using digital image processing based finite element method. Int. J. Rock Mech. Min. Sci. 2008, 45, 749-762. [CrossRef]

48. Xu, W.J.; Wang, S.; Zhang, H.Y.; Zhang, Z.L. Discrete element modeling of a soil-rock mixture used in an embankment dam. Int. J. Rock Mech. Min. Sci. 2016, 86, 141-156. [CrossRef]

49. Xu, Q.; Huang, R.Q.; Cheng, Q.G. Study on soil properties in sliding zone of XIETAN landslide on the threegorges reservoir. J. Eng. Geol. 2003, 11, 354-359.

50. Yu, Q.Q. Characteristic analysis and stability evaluation of landslide in Yunnan. Gansu Water Resour. Hydropower Technol. 2016, 52, 38-46.

51. Han, J.; Wang, J.; Tian, J. Features and formation mechanism of the landslide at TIANGONSI temple in Yaan. J. Geol. Hazards Environ. Preserv. 2015, 26, 3-8.

52. Ye, Q.Y. Borehole inclinometer analysis of landslide in Jiuyu. Highw. Eng. 2017, 3, 112-114.

53. Wang, Y.P.; Xiao, H.Q.; Liu, C. Investigation and study of slope land slide of Minjiang. J. Yibin Univ. 2017, 6, $1-6$.

54. Li, W.; Wang, F.F. Stability analysis of landslide occurring in Fenghuangshan mountain of Tongguan county. Geol. Shanxi 2017, 1, 79-82.

55. Wu, Y.F. Study on Deformation and Failure Mechanism of Landslide of the Soil-rock Mixture in the Qin-ba Mountain. Master's Thesis, Chang'an University, Xi'an, China, 2012.

56. Teng, H.W. Analysis of cause and treatment of landslide in Pu'ge county. Gansu Water Resour. Hydropower Technol. 2017, 53, 22-25.

57. Li, S.; Li, Z.H.; Pang, Z.G. Developing and deforming characteristics of Banensi land slide in Phoenix mountain of Lanzhou City. J. Lanzhou Univ. Nat. Sci. 2015, 5, 790-796.

58. Teng, Y.J.; Huang, X.L.; Wang, S.G. Code for Design of Building Foundation; GB50007-2011; PRC National Standard; China Building Industry Press: Beijing, China, 2012.

59. Chandler, R.J. The inclination of talus, Arctic talus terraces, and other slopes composed of granular materials. J. Geol. 1973, 81, 1-14. [CrossRef]

60. Lindquist, E.S. The Strength and Deformation Properties of Mélange. Ph.D. Thesis, University of California, Berkeley, CA, USA, 1994.

61. Lu, J.W.; Zhong, M.Q.; Zhang, Y.M. JGJ52-2006 Standard of Sand, Stone Quality for Ordinary Concrete and Inspection Method; National Standard of Peoples Republic of China (NSPRC); China Standards Press: Beijing, China, 2007. 
62. Li, Z.Q.; Wang, W.; Shi, S.Q. A Test Method for Shear Strength of Landslide and Deformation of Shear Band. China Patent ZL2015103594909, 29 July 2017.

63. Marsal, R.J. Mechanical Properties of Rockfill, Embankment Dam Engineering; Wiley: New York, NY, USA, 1973; pp. 109-200.

64. Sheng, S.X.; Dou, Y.; Tao, X.Z. Test Methods of Soils; SL237-1999; Ministry of Water Resources of PRC Experimental Standard, Water Power Press: Beijing, China, 1999.

65. Jin, L.; Zeng, Y.W. Particle flow simulation for effects of rock block shape on mechanical behavior of soil-rock mixture. Chin. J. Comput. Mech. 2016, 33, 753-759.

66. Zhu, J.L. Analysis of characteristics and stability of Pianyanzi landslide in Sandun town, Xuanhan County. Subgrade Eng. 2013, 5, 176-180.

67. Ouyang, Z.H.; Li, S.H.; Dai, Z.H. Study on the influence of block to the mechanism of soil mixture. J. Exp. Mech. 2010, 25, 61-67.

68. Sun, R.H. Applied Mathematical Statistics, 3rd ed.; Science Press: Beijing, China, 2017.

(C) 2020 by the authors. Licensee MDPI, Basel, Switzerland. This article is an open access article distributed under the terms and conditions of the Creative Commons Attribution (CC BY) license (http://creativecommons.org/licenses/by/4.0/). 